AperTO - Archivio Istituzionale Open Access dell'Università di Torino

\title{
Combined Microwaves/Ultrasound, a Hybrid Technology
}

\section{This is the author's manuscript}

Original Citation:

Availability:

This version is available http://hdl.handle.net/2318/1634191

since 2018-01-19T15:17:03Z

Published version:

DOI:10.1007/s41061-016-0082-7

Terms of use:

Open Access

Anyone can freely access the full text of works made available as "Open Access". Works made available under a Creative Commons license can be used according to the terms and conditions of said license. Use of all other works requires consent of the right holder (author or publisher) if not exempted from copyright protection by the applicable law. 
This is the author's final version of the contribution published as:

Martina, Katia; Tagliapietra, Silvia; Barge, Alessandro; Cravotto, Giancarlo. Combined Microwaves/Ultrasound, a Hybrid Technology. TOPICS IN CURRENT CHEMISTRY. 374 (6) pp: 79-101.

DOI: $10.1007 / \mathrm{s} 41061-016-0082-7$

The publisher's version is available at:

http://link.springer.com/10.1007/s41061-016-0082-7

When citing, please refer to the published version.

Link to this full text:

http://hdl.handle.net/2318/1634191 


\title{
COMBINED MICROWAVES/ULTRASOUND, A HYBRID TECHNOLOGY
}

\author{
Katia Martina, Silvia Tagliapietra, Alessandro Barge and Giancarlo Cravotto*
}

Dipartimento di Scienza e Tecnologia del Farmaco and NIS - Centre for Nanostructured interfaces and surfaces, University of Turin, Via P. Giuria 9, 10125 Turin, Italy.

\section{Table of Contents}
Abstract
1. Introduction:
2. Combined MW/US reactors
3. Organic reactions under combined MW/US irradiation
3.1. Transesterification reaction
3.2. C-C coupling
3.3. C-heteroatom bond formation
3.4. Heterocyclic compounds
3.5. MW/US assisted digestion
4. Preparation of nanoparticles
5. Plant Extraction
6. Conclusion
Acknowledgments
References

\begin{abstract}
The combination of microwave heating and ultrasound irradiation has been successfully exploited in applied chemistry. Besides saving energy, these green techniques promote faster and more selective transformations. The aim of this review is to provide a practical overview of the complimentary and synergistic effects generated by the combination of microwaves and either ultrasound or hydrodynamic cavitation. This will begin with a brief history, as we outline pioneering achievements, and will also update the reader on recent developments. Such hyphenated techniques are able to offer reliable and efficient protocols for basic chemistry, organic and inorganic synthesis as well as processing. The development of dedicated hybrid reactors has helped scientists to find solutions to new synthetic challenges in the preparation of nanomaterials and new green catalysts. This research topic falls within the confines of process intensification as it facilitates the design of substantially cleaner, safer and more energy efficient technologies and chemical processes.
\end{abstract}

Key words: Microwaves; Ultrasound; Enabling technologies; Hybrid reactors; Synergistic effects.

\section{Introduction}

The use of ultrasound (US) in chemical reactions in solution provides specific activation based on a physical phenomenon: acoustic cavitation. US irradiation causes compression of the liquid followed by its rarefaction and a sudden pressure drop that form small oscillating bubbles of gaseous substances. The bubbles expand until they reach an unstable size; they ca collide and/or violently collaps. Moreover, the interaction of acoustic waves with a chemical system is not merely a way for 
improving dissolution and dispersion as it involves complex physico-chemical phenomena which are currently a matter of advanced research. What makes sonochemistry unique is the remarkable phenomenon of cavitation which is strongly dependent from the solvent vapour pressure, currently the subject of intense research which has already yielded thought-provoking results.

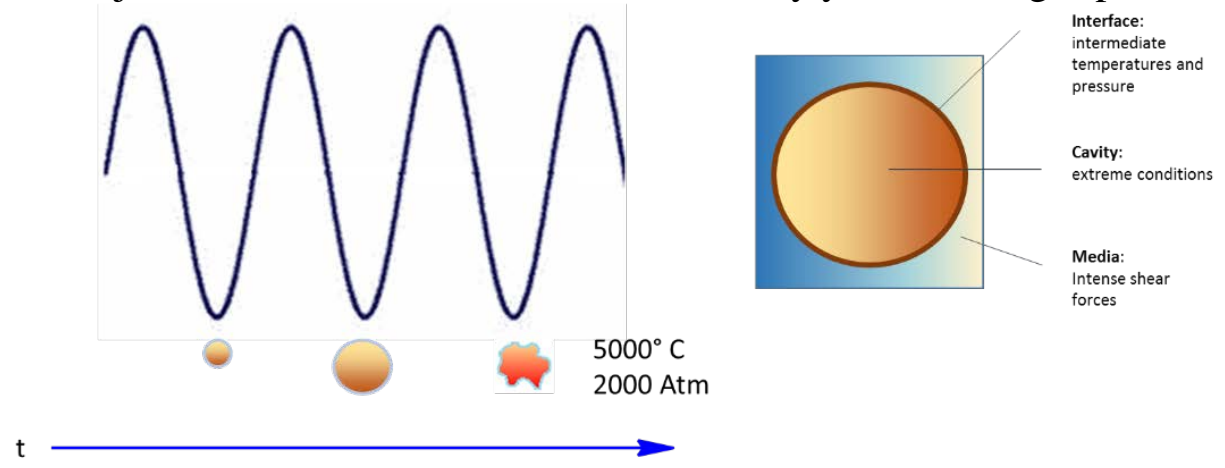

Figure 1 Representation of acoustic cavitation

Microwave (MW) irradiation has been successfully applied in organic chemistry. Spectacular accelerations, higher yileds under milder reaction conditions and higher product purities have all been reported. Indeed, a number of authors have described success in reactions that do not occur by conventional heating and even modifications of selectivity (chemo-, region-, and stereoselectivity). The effect of MW irradiation in organic synthesis is a combination of thermal effects arising form the heating rate, superheating or "hot spots" and the selective adsorption of radiation by polar substances. Such phenomena are not usually accessible by classical heating and the existence of non-thermal effect of highly polarizing radiation is still a controversial topic. Due to the electromagnetic nature of MW non-polar solvent are not fully eligible for this kind of application and they use is limited to the study of "specific MW effect".

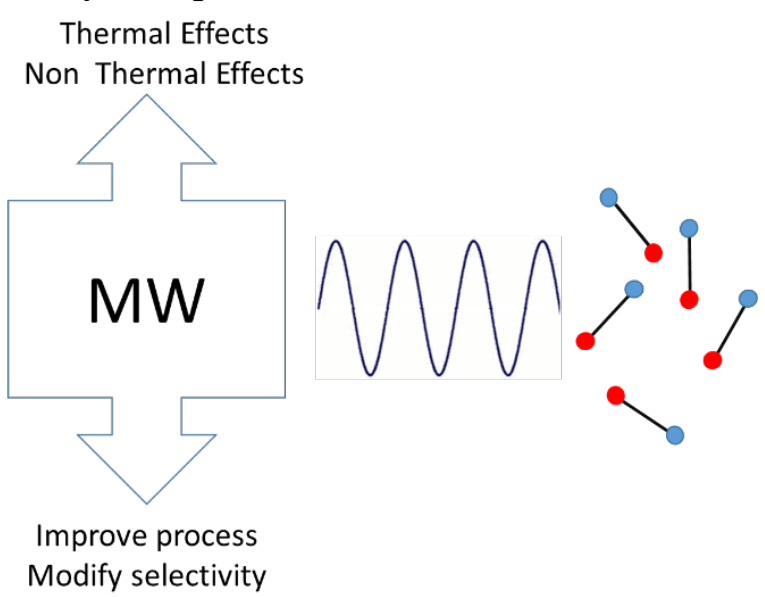

Figure 2 Effect of MW on polar substances

In 1995, Japanese researchers first described the surprising synergistic effects that occurred in sonoand chemi-luminescence experiments carried out under simultaneous microwaves/ultrasound (MW/US) irradiation [1]. This now-typical hyphenated technique gives remarkable improvements in mass transfer, in particular in heterogeneous catalysis or biphasic aqueous systems [2, 3]. Sonochemistry can boast of a longer history than the other techniques, however MW applications have seen impressive growth over the last two decades. While popular wisdom simply associates MW with superior heating and US with efficient agitation, these techniques are capable of doing so much more and this potential has provided additional impulse to their increased use in chemical processes [4]. Combined MW/US irradiation can either be performed in simultaneous mode or otherwise sequentially by circulating the reacting mixture through the two compartments [5]. 


\section{Combined MW/US reactors}

US can be conveyed inside a modified MW oven by inserting a non-metallic-horn through its wall and down into the reaction vessel. These US horns are typically made of ceramic material, quartz, pyrex $^{\circledR}$ or special PEEK ${ }^{\circledR}$ containing glass fibres [6]. Simultaneous MW/US irradiation (SMUI) usually requires constant cooling, which can be provided by a circulating refrigerating fluid that is transparent to MW and thus avoids increasing the temperature to the boiling point, which would result in negligible cavitation. The first prototype, made at the University of Turin (2004), was built around a probe that held a cylindrical quartz horn inserted into a modified domestic oven inside which the PTFE vessel was cooled by a fluid circulating around an external jacket (Fig. 3). Chemat et al. avoided subjecting the horn to the electromagnetic field by using decaline (a low-viscosity apolar liquid) to convey the US waves to the reaction mixture, which was placed in a double-jacketed pyrex vessel inside the oven [7].

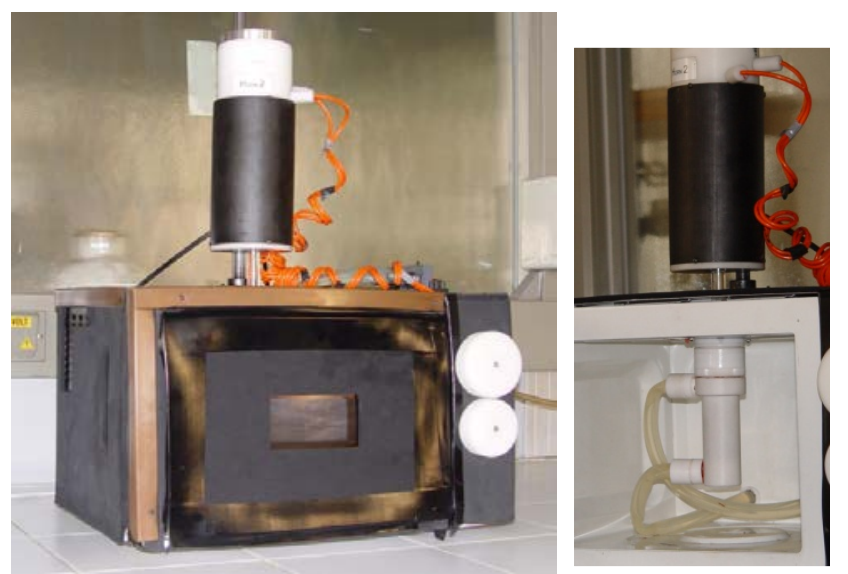

Figure 3. First prototype of SMUI with a cooling system (Authors’ lab)

As part of the authors' collaboration with Milestone Srl (Bergamo, IT), a more professional system was created, seen in figure 4, which is able to monitor and record all of the main parameters.

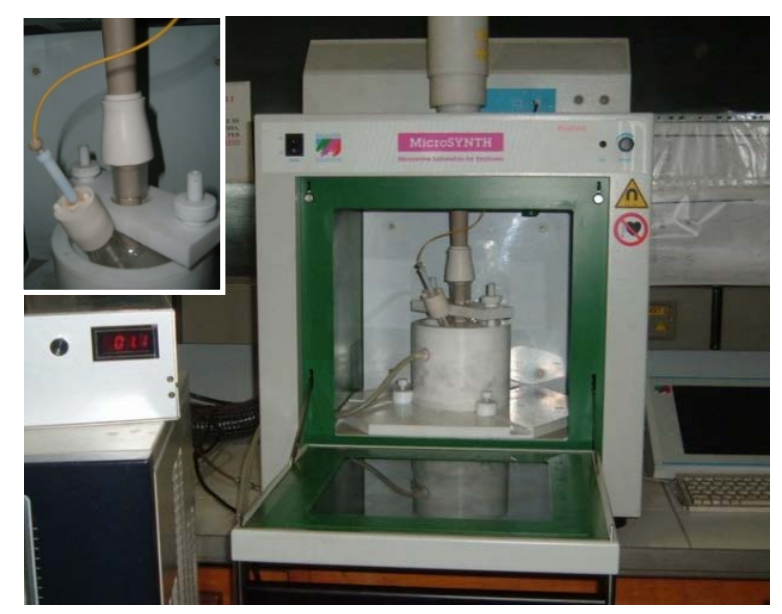

Figure 4. SMUI with a cooling system (Authors' lab)

Combined irradiation can otherwise be achieved using flow loop-reactors for sequential MW/US treatment, meaning that commercially available metallic horns can be used. In these reactors, a pump circulates the reacting mixture through two separate reaction cells; one placed inside the MW oven and the other (fitted with a US probe) outside it (Fig. 5). The Suzuki homo- and cross-couplings of aryl halides and arylboronic acids carried out in this reactor afforded products in higher yields than 
reactions performed under MW or US alone. Commercially available $\mathrm{Pd} / \mathrm{C}$ or $\mathrm{Pd}(\mathrm{OAc})_{2}$ were used as the catalysts and neither phosphine ligands nor phase-transfer catalysts were required. Even electron-deficient aryl chlorides gave acceptable yield [8].

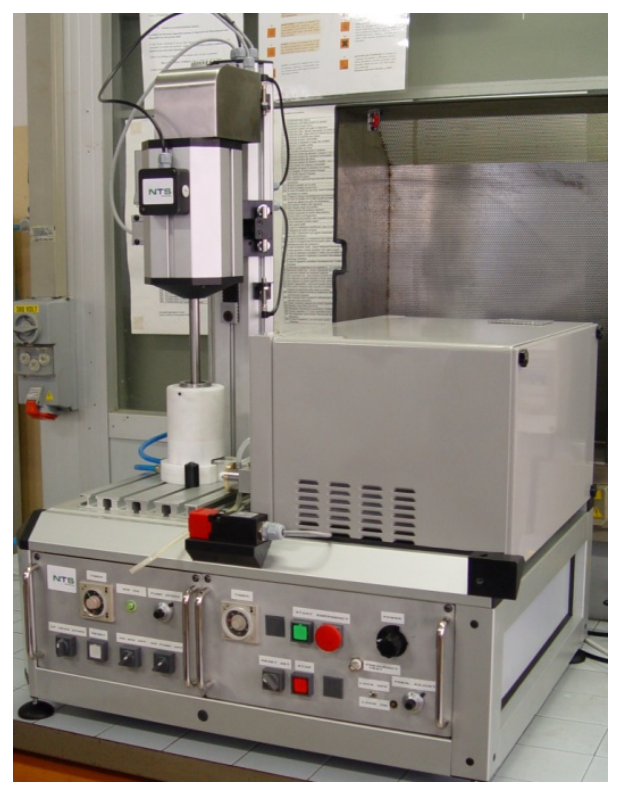

Figure 5. Loop reactor providing MW and US irradiation (Authors’ lab)

A 5 L hybrid MW/US loop reactor prototype has also been used to decontaminate water [9]. The degradation of 2,4-dibromophenol $(0.1 \mathrm{~g} / \mathrm{L})$ by Fenton's reagent was achieved by pumping the aqueous solution through a MW oven and an ultrasonic reactor that consisted of two generators working at 20 and $300 \mathrm{kHz}$.

The degradation of phenol under combined MW/US irradiation, tested in both simultaneous and sequential loop systems, gave impressive synergistic effects, with and without the addition of $\mathrm{H}_{2} \mathrm{O}_{2}$ (Fig. 6 and 7) [10].

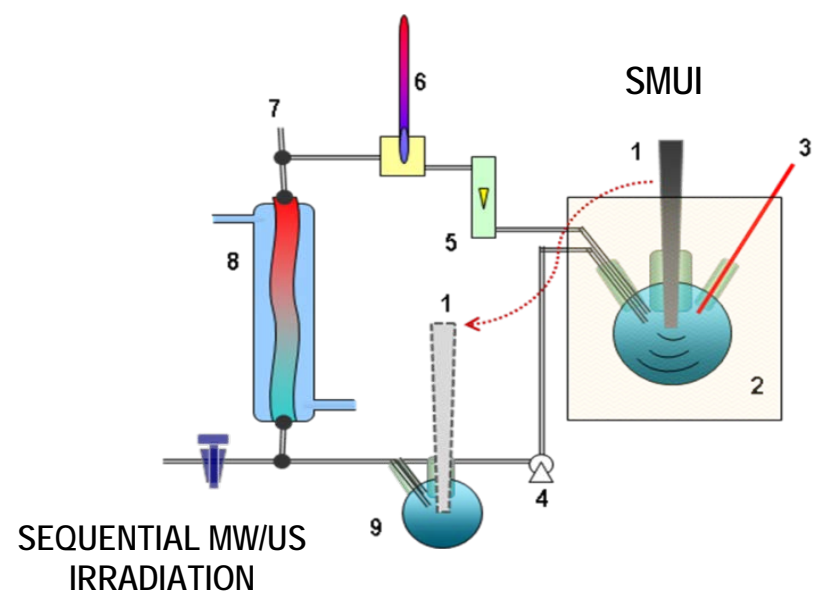

Figure 6. Loop MW/US reactor for simultaneous and sequential irradiation. 1. US non-metallic horn, 2. MW oven, 3. Optical fibre thermometer, 4. Pump, 5. Flow-meter, 6. Thermometer, 7. Inlet and sampler, 8. Heat exchanger, 9. External flask. 


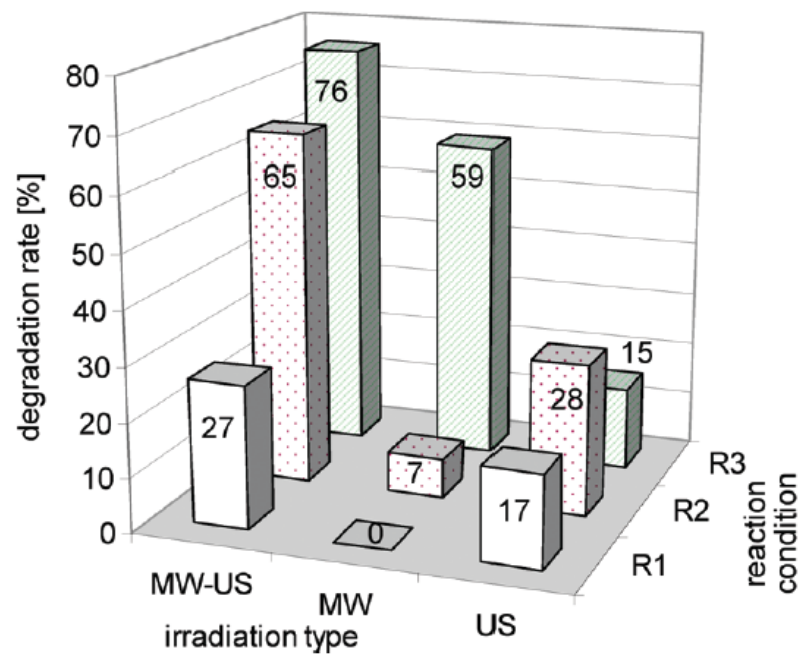

Figure 7. Synergistic effects of SMUI phenol degradation. Reaction conditions: Phenol (1250 mL of $1 \mathrm{mM}$ ). MW: $360 \mathrm{~W}$ irradiated. US: $850 \mathrm{kHz}, 40 \mathrm{~W}$ at $27^{\circ} \mathrm{C}$, flow rate $140 \mathrm{~mL} \mathrm{~min}{ }^{-1}$. R1: without $\mathrm{H}_{2} \mathrm{O}_{2}$, $\mathrm{T}_{\mathrm{MW}} 93{ }^{\circ} \mathrm{C}$, 4 h. R2: $20 \mathrm{mmol} \mathrm{H}_{2} \mathrm{O}_{2}$, $\mathrm{T}_{\mathrm{MW}} 60^{\circ} \mathrm{C}$, 4 h. R3: $20 \mathrm{mmol} \mathrm{H}_{2} \mathrm{O}_{2}$, T $\mathrm{Mw} 93$ ${ }^{\circ} \mathrm{C}, 2 \mathrm{~h}$ (Permission from ref. 10)

Instead of placing the flask into a MW oven, Ragaini et al. used a coaxial dipole antenna as a MW wave guide to deliver MW. A titanium horn was placed orthogonally to the antenna in the same vessel (Fig. 8) [11]. This kind of reactor enables the SMUI of chemical reactions using metallic horns, although its volume is limited.

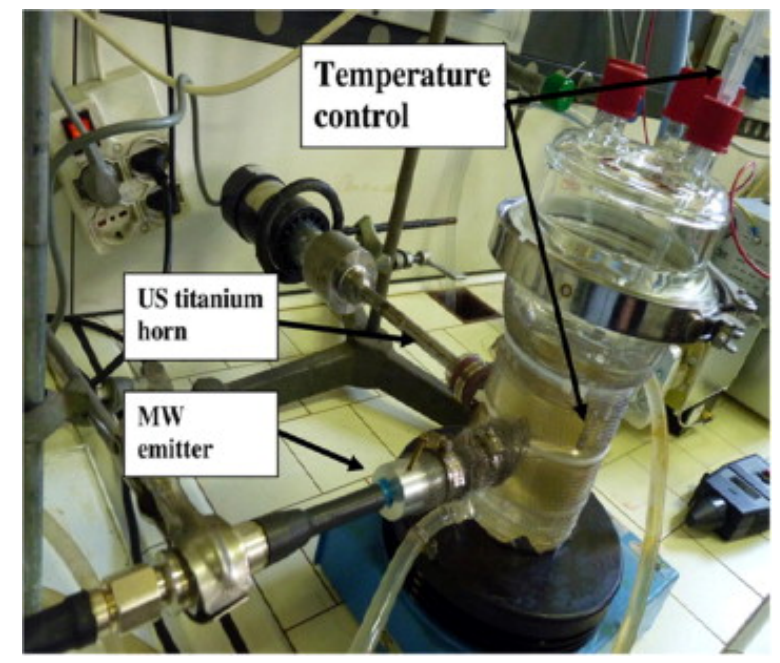

Figure 8. SMUI with MW wave guide and US horn

\section{Organic Reactions under combined MW/US irradiation}

30 years ago, Otteson and Michl described a pioneering gas-phase dehalogenation of organic dihalides using alkali metal vapours in excess argon under MW/US irradiation [12]. Several examples of this marriage appeared in the literature in the decades that were to come as innovative approaches to classical organic reactions and metal-assisted catalysis were described [13]. 


\subsection{Transesterification reaction}

Of the several methods for enhancing oil transesterification that have been reported in the literature, simultaneous MW/US has given excellent results. Besides the high yield and shorter reaction time, superior biodiesel quality and lower energy consumption were observed thanks to optimal mass and heat transfer. The combination of MW and US irradiation is extremely affective in transesterification because microwaves provide faster heating of the reaction media but have mass transfer limitations whereas the ultrasound produces intense physical mixing but lacks the ability to generate/induce high thermal energy for chemical synthesis. By combining the two different techniques in a single reactor the heat and mass transfer limitations and/or requirements of both techniques can be efficiently applied o the transesterification of waste vegetable oil. Martinez-Guerra et al. have developed a very fast protocol for waste vegetable oil to biodiesel production (in $82 \mathrm{~min}$ ) under simultaneous irradiation [14]. Best conditions were: a 6:1 methanol/oil ratio, $0.75 \%$ sodium hydroxide, MW/US power 100W (each source), giving a 98\% yield, which was higher than MW (87\%) or US (90\%) alone. Besides efficiency and selectivity, safety, cost, robustness, and environmental impact were all improved (Fig. 9).

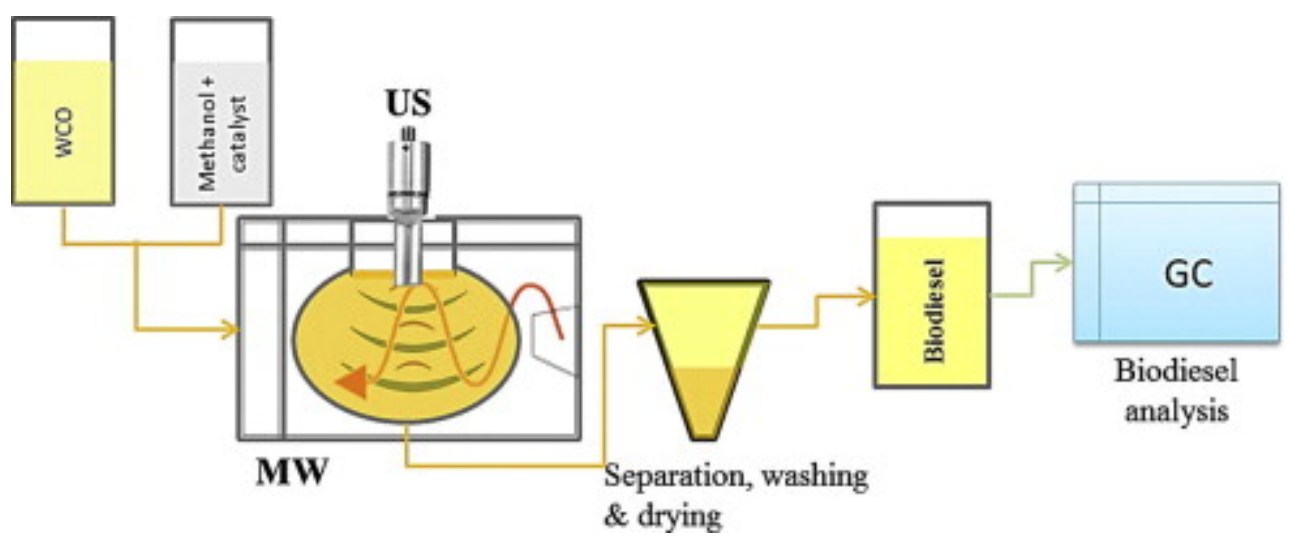

Figure 9. Experimental set-up for transesterification reaction under US/MW (Reproduced with permission from Ref. 14).

The same authors published another work on a MW/US-assisted transesterification by $\mathrm{BaO}$ catalysis. The heterogeneous catalyst as $\mathrm{BaO}$ that do not dissolve or sparkly dissolve in oil or methanol can be easily removed by filtration so to eliminate extensively cleaning and separation processes. [15] in 2016 they evaluated the effect of the type of alcohol on the transesterification reaction of used vegetable oil to produce biodiesel. When MW or US irradiation was applied simultaneously, the biodiesel yields for methanol and ethanol were comparable. Higher for ethanol was observed by individual MW or US irradiation. [16]

Response surface methodology (RSM) has been used by Cravotto et al. to optimize simultaneous MW/US-assisted palm oil transesterification; methanol/oil ratio, catalyst concentration, reaction temperature and irradiation time were all improved [17] (Fig. 10). Full conversion (yield 98\%) was achieved in about $2.2 \mathrm{~min}$ at $58^{\circ} \mathrm{C}(1.09 \%$ catalyst concentration, $7: 3.1$ methanol/ oil molar ratio), whereas the reaction time under classic conductive heating and stirring was about 40-50 min. This work demonstrated that simultaneous irradiation provokes an additive effect, via an increase in contact area between oil and alcohol, leading to an increase in reaction rate. Simultaneous application can also address the issues that are found when carrying out consecutive irradiation. Total energy 
consumption was much lower than in the conventional method (0.36 MJ/l vs. $1.92 \mathrm{MJ} / \mathrm{l}$ (heating + stirring $400 \mathrm{~W}$ for $40 \mathrm{~min})$.

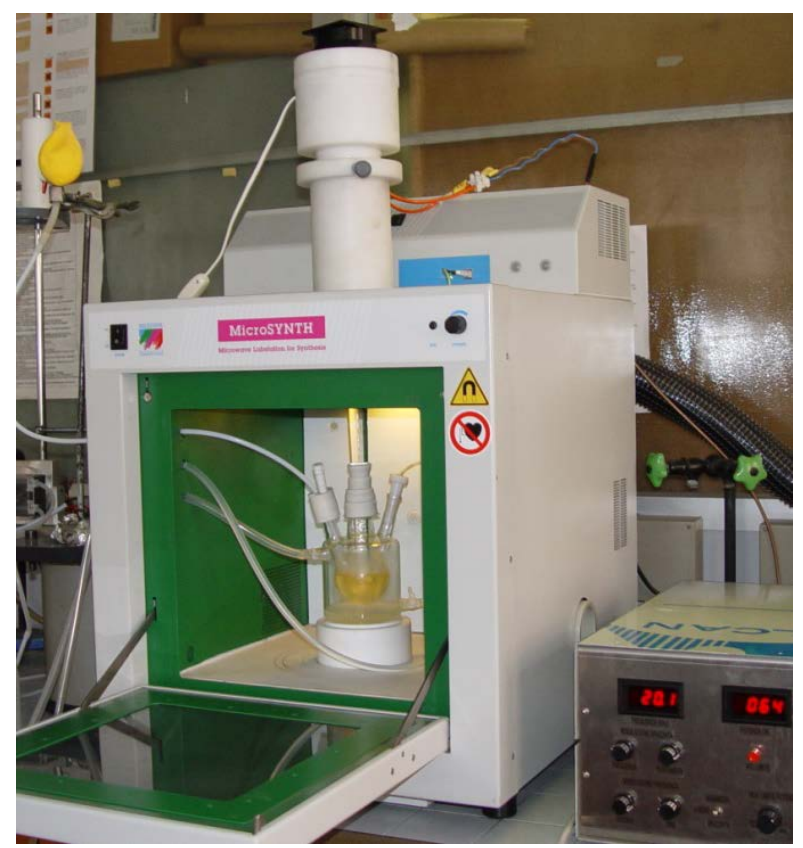

Figure 10. Transesterification under SMUI (Authors’ laboratory).

\subsection{C-C Coupling}

The Heck reaction, one of the most useful protocols in organic synthesis, has become a veritable classic over the last few decades. It has been carried out in all manner of reaction media (organic solvents, water, supercritical $\mathrm{CO}_{2}$, ionic liquids) and, of course, under US and MW irradiation. In 2007, Palmisano et al [18], reported Heck couplings that they had carried out without ligands in air and with very low catalyst loads under simultaneous US/MW irradiation. Ligand-free palladium(II) acetate (0.01-0.1 mol\%) or palladium-on carbon ( $\mathrm{Pd} / \mathrm{C} 10 \%)$, in the $1.0-2.0 \mathrm{~mol} \%$ range, gave most aryl iodides and bromides in high yields under conventional heating $\left(120{ }^{\circ} \mathrm{C}\right)$ in $18 \mathrm{~h}$. Combined $\mathrm{US} / \mathrm{MW}$, however, strongly promoted the reaction and generally decreased reaction times to $1 \mathrm{~h}$. Even barely reactive electron-poor aryl chlorides, such as 4-chloroacetophenone and 1-chloro-4nitrobenzene, reacted with styrene to afford high product yields (Scheme 1). In several cases, the addition of a co-catalyst, either 0.005 mol\% rhodium tris(triphenylphosphine) chloride or 2.0-4.0 mol\% copper(I) salt (iodide or bromide), proved highly advantageous. It is worth noting, however, that 4-Bromo- and 4-chloroacetophenone gave up to $15 \%$ oxidation products, namely the corresponding 4-halobenzoic acid and 4-styrylbenzoic acid. This drawback was avoided by working under a nitrogen atmosphere.
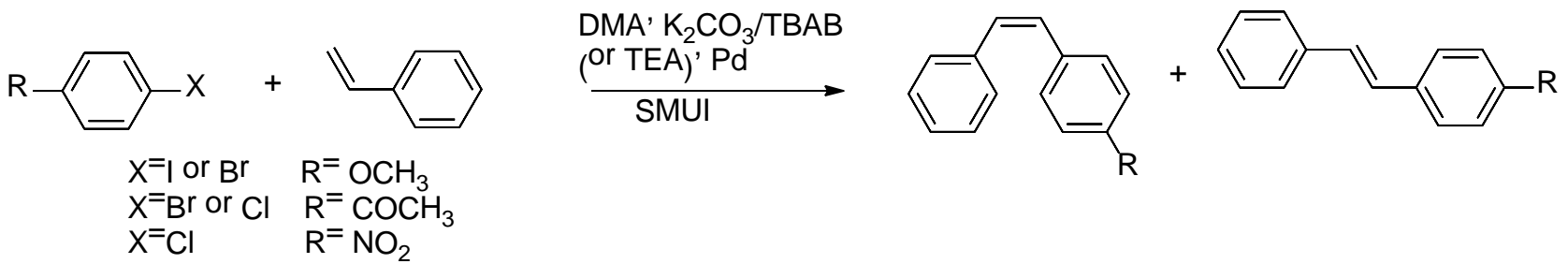

Scheme 1. Schematic representation of a Heck reaction under SMUI (Ref 18). 
Glycerol is a very suitable solvent for both MW and US promoted reactions. Although glycerol alone can be a valid alternative in environmentally friendly organic transformations, its use is still limited in most organic protocols because of the intrinsic reactivity of the - $\mathrm{OH}$ groups and the poor solubility of most organic compounds in it. The micellar catalysis approach may well be an alternative for improving the solubility of organic substrates, while enhancing their diffusion in this particular medium and inhibiting the reactivity of its polyol system. The fascinating possibility of applying SMUI hybrid technology to micellar catalysis in glycerol could lead to the much wider use of green protocols in synthesis and processing. This approach can simultaneously boast of the effective heating of glycerol under MW irradiation, efficient mixing under US and can also avoid side-reactions. In 2014, Sacco et al. [19], described the application of SMUI to this approach using monomodal apparatus equipped with a semiconductor generator and a coaxial cable. The monomode resonant MW cavity was also irradiated with US from the bottom using a suitable sonotrode (indirect sonication).

The authors reported on the efficient SMUI-assisted Ru-catalyzed ring-closing metathesis of diethyl diallyl malonate in glycerol hydrophobic micellar conditions by means of a dicationic surfactant (Fig. 11). The SMUI reaction (US $200 \mathrm{~W}$ and MW $10 \mathrm{~W}$ ) occurred in around $18 \mathrm{~min}$, faster than with MW alone.
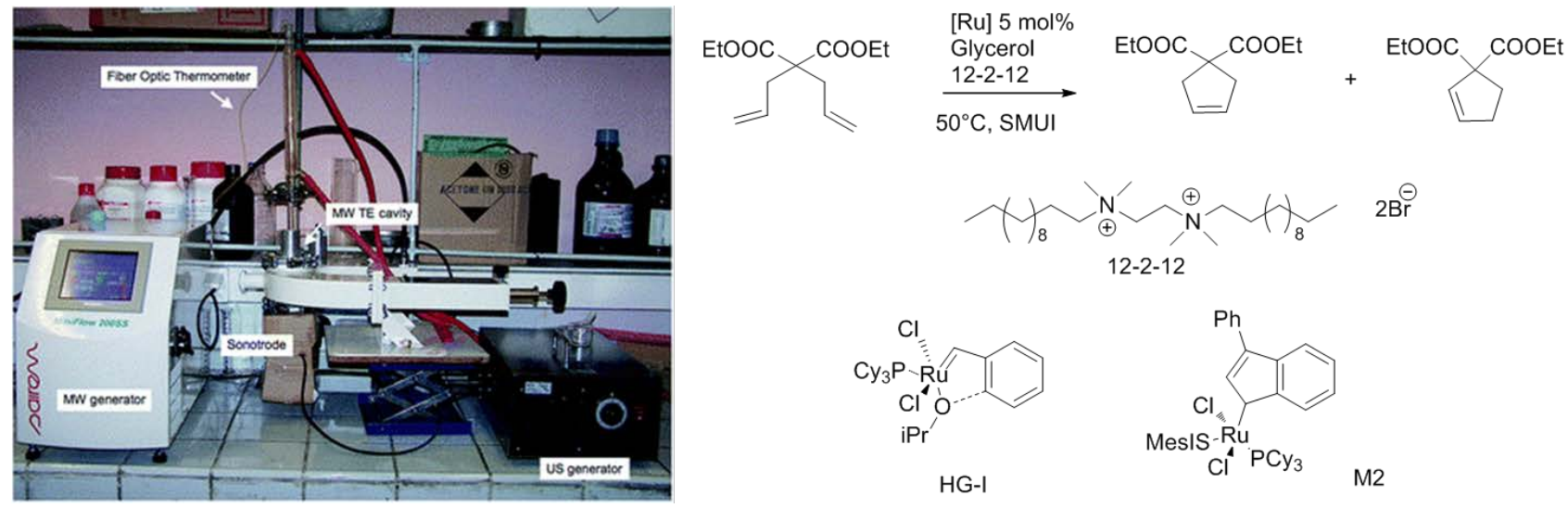

Figure 11. A modified monomode SAIREM Miniflow cavity for SMUI and an example of ringclosing metathesis. Reproduced from Ref. 19 with permission from the Centre National de la Recherche Scientifique (CNRS) and The Royal Society of Chemistry.

Epoxide cleavage by nucleophiles in aqueous media can generally incur competition from water itself, yielding the diol as the by-product. However, under high-intensity US or MW, the attack by the nucleophile was strongly promoted and water no longer reacted. In 2007, Palmisano et al. [20], reported the syntheses of a series of commercially available oxiranes, at different degrees of substitution, using sodium azide and 1-(3-chlorophenyl)piperazine in water at neutral $\mathrm{pH}$ without a metal catalyst. Four different reaction conditions were compared: 1) "on water" conventional conditions at $50^{\circ} \mathrm{C}$; 2) under MW irradiation at $50^{\circ} \mathrm{C}$; 3) under US at $45^{\circ} \mathrm{C}$, and 4 ) under SMUI at $45^{\circ} \mathrm{C}$. The last set of conditions strongly accelerated the cleavage and gave high regioselectivity for unsymmetrical epoxides. The $N$-nucleophile attack took place on the less hindered epoxide carbon, except for in 2-phenyloxirane. Reactions carried out in these conditions are completely antistereoselective, as shown by the exclusive formation of the anti-products in the cyclic epoxide reactions. An example can be found in $(+)-(1 R, 2 S, 4 R)$-cis-limonene 1,2 epoxide that exclusively 
afforded the $1 R, 2 R, 4 R$ stereoisomer in moderate yield (51\%) via reaction with sodium azide, as seen in Scheme 2.<smiles>c1ccc(C2CO2)cc1</smiles><smiles>C[As](C)[Se]</smiles><smiles>N#CC(CO)c1ccccc1</smiles><smiles>N#CCC(O)c1ccccc1</smiles><smiles>Clc1cccc(N2CCNCC2)c1</smiles>
$28 \%{ }^{\alpha}, 61 \% \beta$ $\mathrm{NaN}_{3}$ $95 \% \beta$<smiles>C=C(C)[C@@H]1CC[C@@H]2O[C@]2(C)C1</smiles>

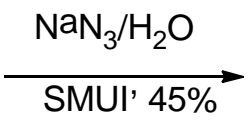<smiles>C=C(C)C1CCC(O)C(C)C1</smiles>

Scheme 2. Schematic representation of epoxide opening under SMUI (Ref 20)

The Huisgen 1,3-dipolar cycloaddition of azides and acetylenes leading to 1,2,3-triazoles and catalyzed by $\mathrm{Cu}$ (I) salts is one of the most versatile "click" reactions. In 2007, the authors reported a series of optimized protocols and new applications of this reaction starting from several substrates [21]. Comparisons of heterogeneous vs homogeneous catalysis (as based on charcoal-supported $\mathrm{Cu}(\mathrm{II})$ or $\mathrm{Cu}(\mathrm{I})$ ), as well as conventional heating vs MW irradiation vs SMUI were made. Excellent results were obtained even with bulky molecules, such as azido $\beta$-cyclodextrins ( $\beta$-CD), which afforded triazole cycloaddition with benzyl bromide and phenylacetylene. MW and SMUI dramatically accelerated the reaction in all cases (Scheme 3), the latter by means of a non-metallic US horn placed in the MW cavity. Very interesting results have been also achieved using metallic copper (turnings) instead of $\mathrm{Cu}(\mathrm{I})$ or $\mathrm{Cu}(\mathrm{II})$ salts [22]. The simultaneous use of US and MW promotes the reaction between $\mathrm{CuO}$ and $\mathrm{Cu}$ on the metal surface to give the catalytic species $\mathrm{Cu}_{2} \mathrm{O}$ (US promoted reaction), while allowing the temperature required for 1,3-dipolar cycloaddition (MW enhanced reaction) to be reached at the same time. The combined MW/US approach gave better yields (in the same reaction time) than MW or US used alone. This new protocol was successfully applied to the derivatization of 6-monoazido-6-monodeoxy- $\beta$-ciclodextrin and 6-monoazido-6-monodeoxy2,3,6-O-permethyl- $\beta$-ciclodextrin with phenylacetilene. 


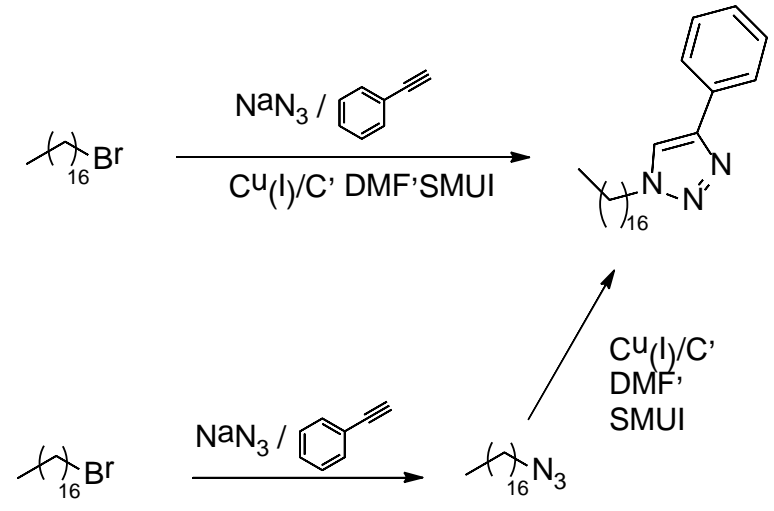

Scheme 3. SMUI promoted CuAAC reaction (Ref 21)

Cinnamic acid and its derivatives are important reagents in organic synthesis as both intermediates and final products. They are routinely obtained from the reaction between aromatic aldehydes and malonic acid (Knoevenagel-Doebner reaction) in organic solvents, catalysed by either primary or secondary amines. SMUI furnished significant rate enhancements and improved yields in the heterogeneous organic reactions. The SMUI technique has been applied by Peng and Song [23] for the preparation of 3-aryl acrylic acids in aqueous media with excellent yields (73-93\%), as seen in Scheme 4. The presence of electron-withdrawing or electron-releasing groups on the substrates only had a slight influence on the yields. Results showed that the SMUI reaction proceeded much faster than under classic reflux; 65s vs $7 \mathrm{~h}$. An additional advantage of using water as the solvent is the fact that many organic products can be separated via simple filtration or decantation from the resulting mixture.

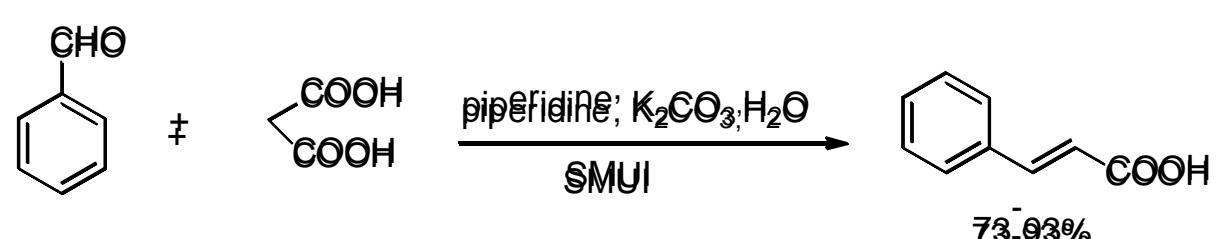

Scheme 4. Knoevenagel-Doebner reaction promoted by SMUI (Ref 23)

\subsection{C-Heteroatom bond formation}

The Williamson synthesis of ethers usually makes use of an alkali-metal salt of the hydroxy compounds and halides working in either organic solvents or under phase transfer catalysis. The direct etherification of phenols with an alkylating agent and a base is, however, troublesome; the etherification of nitrophenols requires aprotic solvents if large excesses of alkylating agents and side reactions are to be avoided. Moreover, the selective monoetherification of bisphenols is not an easy task because it is inevitably accompanied by bietherified products. In this context, Peng and Song [24] reported a SMUI-assisted etherification that afforded a series of benzyl phenyl ethers and diphenyl ethers in good yields without the need for phase-transfer catalysis (Scheme 5). Control experiments, which were carried out under conductive heating and stirring, clearly displayed the great advantage of SMUI; benzyl phenyl ether was obtained in $16 \mathrm{~h}$ vs $2 \mathrm{~min}$ and at $41 \%$ vs 83\% yield, respectively. 


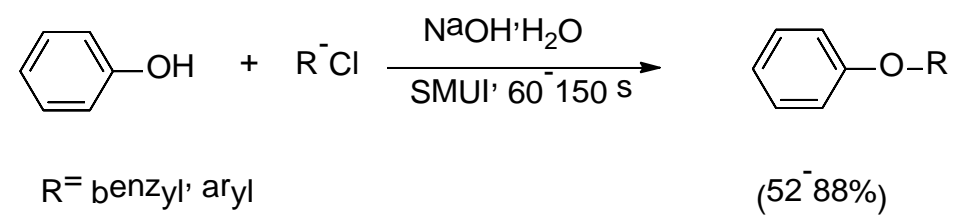

Scheme 5. SMUI promoted Williamson ether synthesis (Ref 24)

The solvent and surfactant free SMUI procedure has been applied to the synthesis of hydrazides from esters and hydrazine monohydrate by the same authors [25]. Acyl anhydrides and acid chlorides both react rapidly with hydrazine to give hydrazides, but it was not possible to stop the monoacylation reaction. The most widely used method for the preparation of hydrazides is the hydrazinolysis of the corresponding esters with hydrazine monohydrate. This is, however, a reaction with some drawbacks, such as the long reaction time and the diacylation products. Using the hydrazinolysis of methyl salicylate as a model system, the reaction was studied under a number of different reaction conditions (US, MW and SMUI), as seen in Scheme 6. Results clearly show that SMUI achieved the best results in terms of both reaction time and yield (84\% vs $73 \%$ in 40 sec. instead of 9 h under conventional heating with reflux).

$$
\begin{gathered}
\text { R coOme }^{-} \frac{75 \% \mathrm{~N}_{2} \mathrm{H}_{4} \mathrm{H}_{2} \mathrm{O}}{\mathrm{SMUl}^{\prime} 20^{-} 65 \mathrm{~S}} \rightarrow \mathrm{R}^{-} \mathrm{CONH}_{2} \mathrm{NH}_{2} \\
\mathrm{R}^{=} \text {alkyl' aryl }
\end{gathered}
$$

Scheme 6. Schematic representation of the synthesis of hydrazide under SMUI (Ref 25)

Aromatic azo and azoxy compounds are important dyes and are widely used as analytical reagents, reducing agents, stabilizers and polymerization inhibitors in biological and chemical research. Aromatic azo compounds are traditionally synthesized via the coupling of diazo compounds with amines or phenols, the oxidation of hydrazine and hydrazo compounds, the reduction of nitro compounds in alkaline solution or the molecular rearrangement of diazoamines. The formation of azobenzene via the oxidation of aniline in basic solution has been known since 1960 and the mechanism was explained using sonochemical experiments in water. US generated $\mathrm{H} \cdot$ and $\mathrm{OH}$ • radicals that converted aniline to $\mathrm{PhNH} \cdot$ and $\mathrm{PhN} \cdot$ radicals that combined to yield $\mathrm{PhNHNHPh}$ and $\mathrm{PhN}=\mathrm{NPh}$. The oxidation of aniline using $\mathrm{MnO}_{2} / \mathrm{SiO}_{2}$ under $\mathrm{MW}$ irradiation (420W) for just 4 min gave azobenzene in an 84\% yield. In 2008, Ondruschka et al. [26] reported an efficient MW/US procedure for the preparation of azo and/or azoxy compounds from primary aromatic amines (Scheme 7). $p$-methylaniline and p-ethylaniline conversions of more than $70 \%$ were obtained in 20 min under MW or SMUI, whereas 57 and 54\% p-ethylaniline conversions were observed under US irradiation and plain heating in a water bath, respectively. SMUI significantly enhanced the conversion of $p$ chloroaniline as well. DMF is commonly used in MW irradiation chemistry as it is a good polar, aprotic solvent with a high boiling point. However, when present, it leads to the formation of formamidine and other by-products resulting in poor selectivity towards azo and azoxy products. No by-product was formed when the amount of water in the medium was increased from 15 to $35 \mathrm{ml}$. However, the yields of azo and azoxy compounds also decreased in this case. Other solvents such as dimethyl sulfoxide (DMSO), acetonitrile and ethanol, have been studied with the aim of avoiding the formation of formamidine and other by-products. 


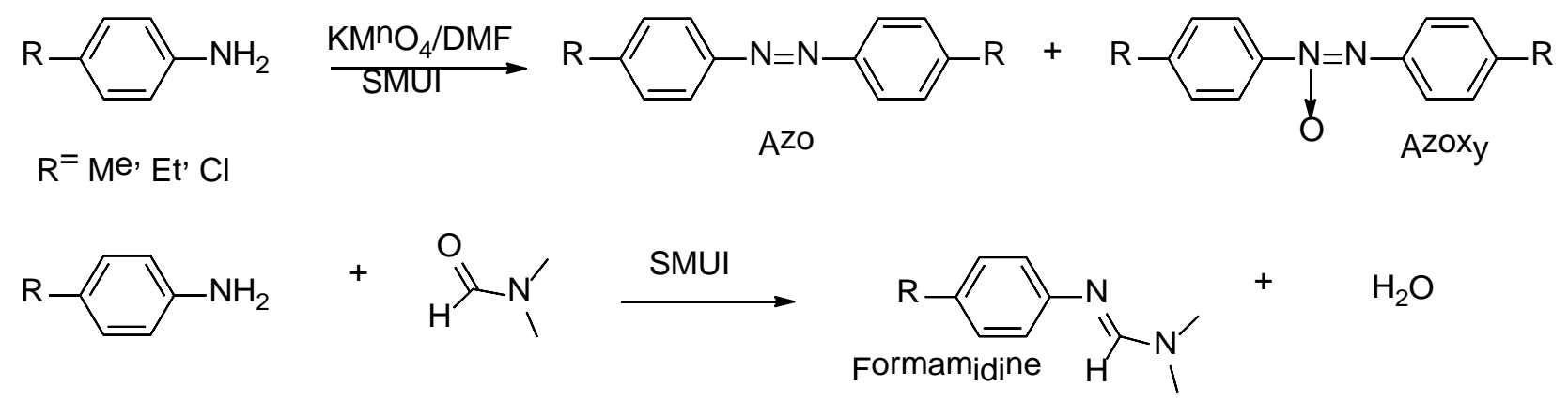

Scheme 7. Schematic representation of the synthesis of azo and/or azoxy compounds (Ref 26)

\subsection{Heterocyclic compounds}

Interest in the synthetic applications of SMUI in palladium-catalyzed reactions with very low catalyst loads, [27] led the authors to investigate the efficiency of this technique for the selective functionalization of 3,5-dichloro-2-(1H)-pyrazinones in 2010. In spite to the poor reactivity in Pdcatalyzed Suzuki and Heck reactions owing to the 5-chloro atom, SMUI strongly promoted the reaction leading to good yields by reducing the extent of degradation that can arise from prolonged heating. SMUI requires an efficient cooling system if strict temperature control is to be achieved and superheating, that would hamper cavitation, is to be prevented. This can be attained by circulating a MW-transparent refrigerated fluid such as Galden ${ }^{\circledR}$; a perfluoropolyether with a high boiling point and low viscosity. A Heck reaction of 3,5-dichloro-2-(1H)-pyrazinones with styrene was carried out using three different techniques: conventional heating, MW and SMUI (Scheme 8). Reactions were carried out in dimethylacetamide (DMA) under a nitrogen atmosphere in all cases. Yields were generally low because of partial degradation and the formation of by-products when the reaction was stirred under conductive heating, whereas yields were greatly improved under MW irradiation and were even better under MW/US irradiation. Complete conversion was observed after only 20 min with excellent reproducibility. The same 3,5-dichloro-2-(1H)-pyrazinones were subjected to SuzukiMiyaura cross-couplings with pnenylboronic acid in dimethylacetamide using very low catalyst loading $(0.005 \mathrm{mmol}$ of tetrakis ( triphenylphosphine) palladium) and caesium carbonate as the base, as seen in Scheme 9. Yields increased from $7-14 \%$ under conventional heating to $63-86 \%$ under SMUI, which proved itself to be a fantastic tool for the chemical decoration of pyrazinones. Simultaneous MW/US irradiation greatly improved the kinetics and yields of these chemical modifications due to the optimal heat-and mass-transfer that they provide.

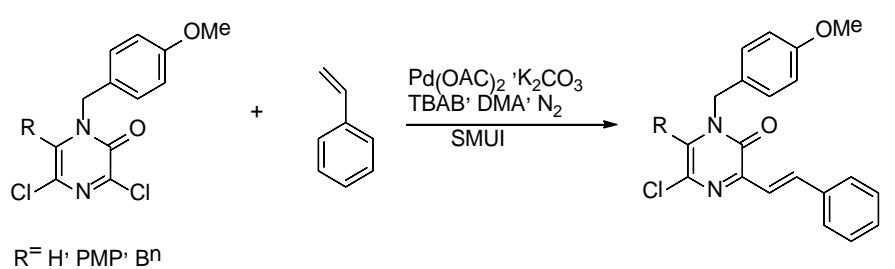

Scheme 8. Heck reaction of 3,5-dichloro-2-(1H)-pyrazinones with styrene (Ref 27) 


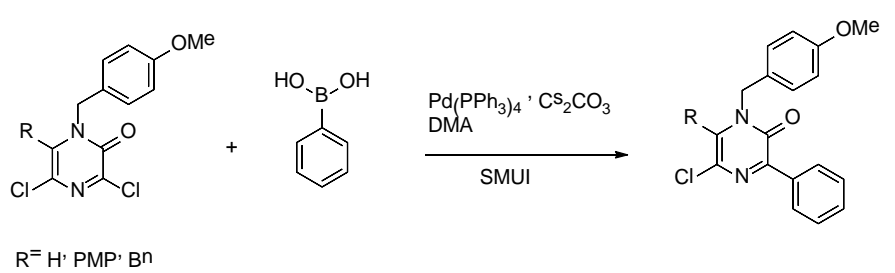

Scheme 9. Preparation of 3,5-dichloro-2-(1H)-pyrazinones (Ref 27)

The first generation of ionic liquids (ILs) that saw widespread use was mainly composed of cations, such as dialkylimidazolium and alkylpyridinium derivatives, and anions, such as chloroaluminate and other metal halides which have been described as toxic and non-biodegradable. This generation of ILs was also oxygen-sensitive and can only be handled under inert-gas atmosphere. Research was thus directed towards the synthesis of air- and water-stable ILs, the second generation of ILs. The water- and oxygen-reactive anions were either replaced by halides (Cl-, Br-, I-) or anions, such as BF4-, PF6- and $\mathrm{C}_{6} \mathrm{H}_{5} \mathrm{CO}_{2}$, which are stable in water and air. This second generation of ILs attracted a great deal of attention from the wider scientific community and has been providing interesting and novel applications in a number of areas. The "green” properties of ILs are linked to their negligible vapour pressure and flammability as well as their ease of recycling. However, their biodegradability is still open to debate and further toxicological studies are required if we are to ascertain their complete safety. They are usually prepared over two consecutive steps: (i) the quaternarization of a nitrogen-bearing compound (Menshutkin reaction) and (ii) the exchange of the halide with a different anion (metathesis). Non-conventional techniques, such as irradiation with microwave (MW) and power ultrasound (US), have been successfully employed in the synthesis of ILs and have cut down reaction times and improved yields. In 2007, Cravotto et al. [28] described an efficient one-pot synthesis of second-generation ILs, (Menshutkin reaction and anion metathesis) under SMUI; a series of ILs with 1-methylimidazole or pyridine cores were obtained in high yields in just a few minutes (80-97\% isolated). The yields for the Menshutkin reaction are strongly temperature-dependent, meaning that strict temperature monitoring, using either optical-fibre thermometers or infrared (IR) pyrometers, is required (Scheme 10). Preliminary experiments were also carried out on chloroalkanes. The one-pot synthesis of [C8 mim] $\left[\mathrm{PF}_{6}\right]$ from 1-chlorooctane under SMUI for $10 \mathrm{~min}\left(140{ }^{\circ} \mathrm{C}\right)$ only gave a moderate yield (55\%). Work on optimizing the protocol for use with notoriously poorly reactive chloroalkanes is in progress.. An efficient cooling system, which allows MW and US power levels to be increased sufficiently, was used. The reaction yield rose to $97 \%$ when carried out under external cooling at $140 \circ \mathrm{C}(10 \mathrm{~min})$.

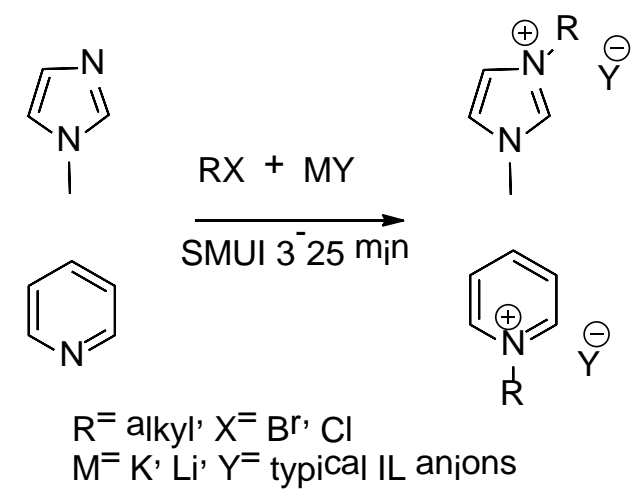

Scheme 10. Preparation of ionic liquids (Ref 28) 


\subsection{MW/US assisted digestion}

Ammonia and organic nitrogen can be analytically determined using the Kjeldahl method which requires a previous sample digestion. A systematic study has been carried out, by Domini et al. [29], on a series of aminoacids and on real samples where the classical Kjeldahl approach and MW/US combined method were compared. The total nitrogen values determined by the MW/US combined digestion method are closer to theoretical ones than those obtained using the classical approach. Furthermore, the mineralization time was reduced from 30 minutes (classical approach) to 7 minutes (MW/US). The process was carried out in a glass round bottom flask heated in a professional microwave oven. A pyrex horn was inserted into the flask in order to simultaneously irradiate the sample with US and MW.

\section{Nanoparticles}

Nanoparticles (NPs) are becoming key components of a wide range of applications. Research encompasses numerous disciplines, including nanotechnology, pharmaceuticals manufacture, chemistry, physics, optical components and polymer science. The size, morphology and dimensionality of NPs can strongly affect the properties of nanostructured materials. Nanostructured metallic and semiconducting materials of various structures and morphologies have recently received a great deal of attention due to their novel applications, peculiar properties and quantum size effects [30]. Nanostructured materials have thus been prepared via a variety of synthetic methods, including gas phase techniques, liquid phase methods (e.g. reduction of metal salts), and mixed phase approaches (e.g., synthesis of conventional heterogeneous catalysts on oxide supports). However, reducing agent strength as well as interactions with stabilizing agents and solvents can affect the size and shape of metal nanoparticles in the production of metallic NPsThe use of MW irradiation in this context is not affected by safety concern due to the high dilution of the metal in the ab initio preparation of nanoparticles. Of particular interest here is the use of MW radiation as the heat source as it can produce high quality nanoparticles in a short time [31]. Moreover, US irradiation has been extensively examined in this field over many years [32, 33], and is now positioned as one of the most powerful tools in nanostructured material synthesis. It was only natural to consider the combination of MW and US irradiation which has, in fact, recently been used to synthesize nanoparticles in a short time and was also able to tune particle properties and size [34].

SMUI has been used to generate copper nanoparticles via $\mathrm{Cu}(\mathrm{OAc})_{2}$ reduction by hydrazine hydrate in ethylene glycol [35]. The nanoparticles were fully characterized using X-ray diffraction (XRD) and transmission electron microscopy (TEM) to confirm that the spherical nanoparticles were made of pure metallic copper. $\mathrm{Cu}$ nanoparticles then catalyzed nitrobenzene reduction with hydrazine hydrate. The reaction was repeated with $\mathrm{Cu}(\mathrm{OAc})_{2}$ under SMUI to obtain the reduced aniline and $\mathrm{Cu}$ nanoparticles that were isolated by centrifugation. The optimized protocol was performed with $20 \%$ $\mathrm{Cu}(\mathrm{OAc})_{2}$ and 3 eq of hydrazine hydrate and was heated at $105-110^{\circ} \mathrm{C}$ in ethylene glycol. The same reaction, performed under conventional conditions lasted 12 hours and had a yield of 52\%, whereas the SMUI promoted reaction took $4.5 \mathrm{~min}$ and the yield was 97\% (Scheme 11).

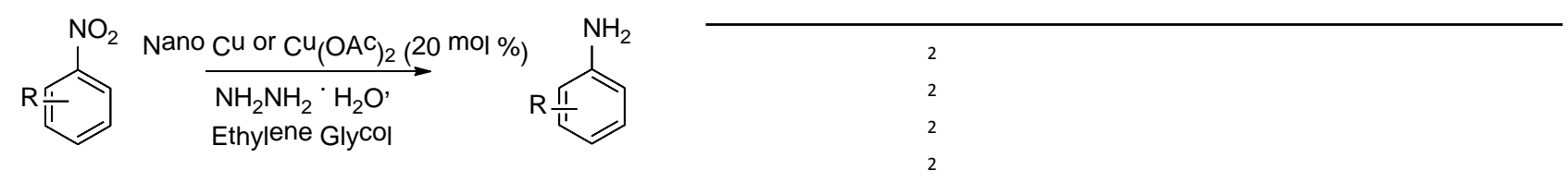


Scheme 11. Reaction scheme and conversions of the copper catalyzed reduction of nitrobenzene under differing conditions (Ref 35)

US and MW irradiation were also used sequentially to obtain solid supported Pd catalyst for the semihydrogenation of alkyne to alkene [36]. Pd was reduced using US irradiation and supported under MW promotion to obtain Pd clusters of approximately $100 \mathrm{~nm}$. This catalyst showed enhanced activity in the semi-hydrogenation reaction and high selectivity. This method is truly a novel and green route to the production of Pd nanoparticles, even in the absence of a surfactant.

The beneficial effects of MW and US irradiation in the preparation of $\mathrm{CuO}$ nanoparticles has also been demonstrated by Zhu et al. as they aimed to obtain nanofluids with enhanced thermal conductivity [37]. In this study, $\mathrm{Cu}(\mathrm{OH})_{2}$ was converted to $\mathrm{CuO}$ in water under SMUI. The suspension was treated for $30 \mathrm{~min}$ in an US disrupter for the conversion from green to puce, while a subsequent 3 min of MW irradiation were enough to obtain the black nanofluid. The authors demonstrated that the transformation did not complete and the particles were aggregate when US only was used and that, analogously, some large aggregates were obtained when MW irradiation alone was used.

Nanostructures, such as wires, tubes and ribbons, have fast become the focus of intensive research in recent years because their small dimensions can be employed both for the efficient transport of electrons and optical excitation. Nowadays, light emitting diodes, solar cells, single electron transistors, lasers and biological labels are currently making full use of these ideal one-dimension nanostructures. Developing an efficient and sustainable approach to their preparation is, understandably, a subject of great interest and the microwave/ultrasound combination is showing great promise in their environmentally benign production. Surfactants and ionic liquids are commonly used as templates to promote the formation of nanostructures. The combination of MW and US irradiation and the use of 1-butyl-3-methylimidazolium bromide [BIMB] $\mathrm{Br}$ has been successfully employed for the rapid the synthesis of $\mathrm{Pb}(\mathrm{OH}) \mathrm{Br}$ nanowires [38]. $\mathrm{Pb}(\mathrm{OAc})_{2} \cdot 3 \mathrm{H}_{2} \mathrm{O}$ and [BIMB] $\mathrm{Br}$ were dissolved in deionised water and irradiated for $10 \mathrm{~min}$ by MW-US (50 W - $50 \mathrm{~W}$ ) irradiation. A comparison of nanowires obtained via conventional heating $\left(70{ }^{\circ} \mathrm{C}, 24 \mathrm{~h}\right)$, those by $\mathrm{MW}$ irradiation and US irradiation alone and finally by the combined method highlighted the drastic differences in diameter and length of the nanowires produced by the differing methods. Under conventional conditions, $\mathrm{Pb}(\mathrm{OH}) \mathrm{Br}$ typically crystallized as a multiangular prism of 20-30 um diameter and 2-3 $\mathrm{mm}$ of length. MW irradiation alone produces a uniform and smooth morphology, while ultrasound alone resulted in less uniform wires. Under combined US-MW irradiation furnished increased yields of straight and smooth wires (80-800 nm diameter and 50-100 um length). A dramatic reduction in crystallization time ( $24 \mathrm{~h}$ to $80 \mathrm{sec}$ ) was also observed, which confirms that SMUI leads to the fast growth of crystal seed masses and causes a depletion in reaction nutrients over a short period of time, producing thinner and shorter wires (Fig. 12). 


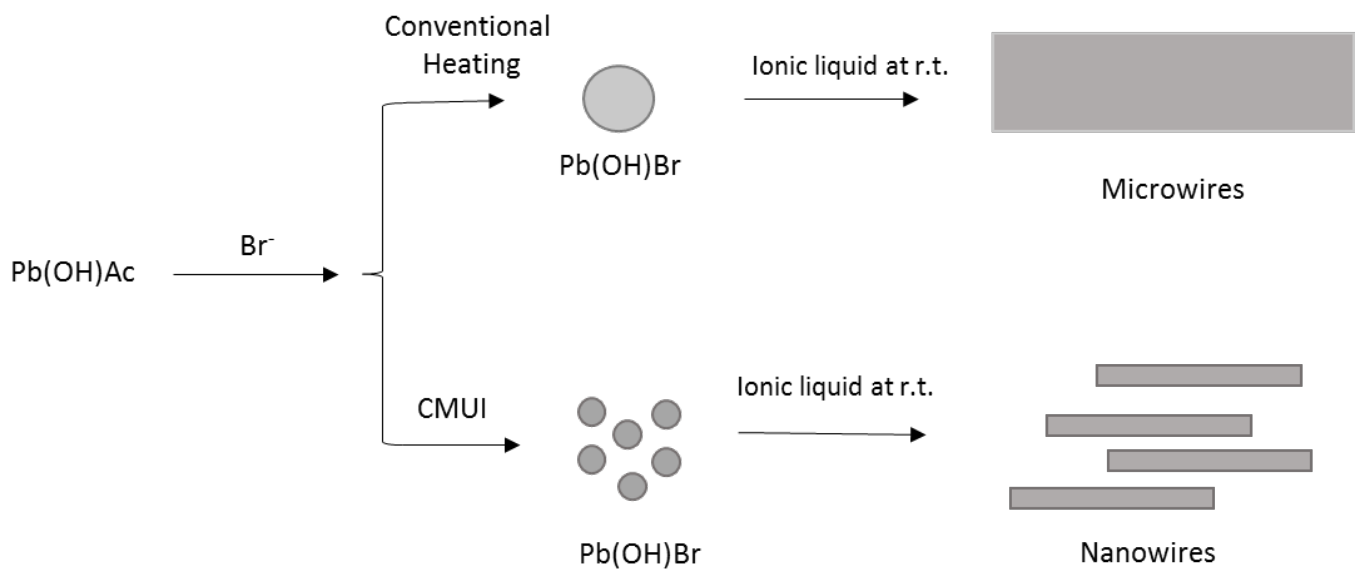

Figure 12. Schematic representation of $\mathrm{Pb}(\mathrm{OH}) \mathrm{Br}$ nanowire formation. Ref 29

Of the different types of absorbing material used for thin-film solar cells, $\mathrm{Cu}_{2} \mathrm{ZnSnS}_{4}$ (CZTS) is one of the most promising as it contains earth-abundant, low cost and nontoxic elements. Many approaches to prepare CZTS thin films have been described in the literature in an attempt to reduce preparation costs. High cell efficiency is currently obtained via a non-vacuum based approach in the absence of hydrazine, which is highly toxic, reactive and requires delicate handling and storage. The main methods for the preparation of CZTS nanoparticles include hot injection [36], solvothermal [40], mechanochemical [41] and microvave irradiation [42]. Microwave irradiation has been combined with ultrasound in order to reduce nanoparticle aggregation; Wang W. et al. obtained CZTF nanoparticles by exposing a solution of zinc acetate dihydrate, tin(II)chloride dihydrate, copper(II)nitrate trihydrate and thioacetamide in polyethylene glycol 400 to simultaneous microwave-ultrasound irradiation (MW power 800 and $400 \mathrm{~W}$ ). The precursors were irradiated at different temperatures, from 130 to $180^{\circ} \mathrm{C}$, for $30 \mathrm{~min}$ and, after the nanoparticles were characterized, it was observed that crystallinity, to form hexagonal-plate-like-nanoparticles, increased with increased temperature [43]. Long F. et al. have described the preparation of wurtzite, rather than kesterite phase, CZTF via the addition of a solution of thiourea in polyvinylpirrolidone to a solution of copper(II)acetate monohydrate, zinc acetate dehydrate and tin(IV)chloride dihydrate in PVP at 150 ${ }^{\circ} \mathrm{C}$ under SMUI. The crystalline structure of CZTF was fully characterized by XRD, FESEM, EDS and TEM and the hexagonal prisms obtained were found to measure $0.5-2 \mu \mathrm{m}$ wide and $5-12 \mu \mathrm{m}$ long [44].

Europium or terbium activated phosphors, with characteristic lanthanide luminescence, were assembled under SMUI to obtain nanocrystals [45]. $\mathrm{Bi}\left(\mathrm{NO}_{3}\right)_{3} \cdot 5 \mathrm{H}_{2} \mathrm{O}, \mathrm{Ln}\left(\mathrm{NO}_{3}\right)_{3} \cdot 6 \mathrm{H}_{2} \mathrm{O}$ and $\mathrm{NH}_{4} \mathrm{VO}_{3}$ were irradiated by MW and US (MW power $400 \mathrm{~W}$ ) in water at $80^{\circ} \mathrm{C}$ for $1 \mathrm{~h}(\mathrm{Ln}=\mathrm{La}, \mathrm{Lu}, \mathrm{Tb}, \mathrm{Eu})$. The ultrasonic probe worked in pulsed mode (0.1 s and inter-pulse $0.2 \mathrm{~s})$. SEM images showed quasi 1-D nanounits of $\mathrm{BiVO}_{4}: \mathrm{Eu}^{3+}$ of $60-80 \mathrm{~nm}$ average diameter (Fig. 13 and 14). When SMUI was exploited to prepare $\mathrm{GdBO}_{3}$ : $\mathrm{Eu}^{3+}$, a spontaneous nano-assembly was formed in flower-like morphology. Characteristic $\mathrm{Eu}^{3+}$ emissions were detected upon excitation. The $\mathrm{La}_{\mathrm{x}}-\mathrm{Lu}_{1-\mathrm{x}} \mathrm{PO}_{4}: \mathrm{Tb}^{3+}$ particle exhibited strong green emissions under UV excitation. 

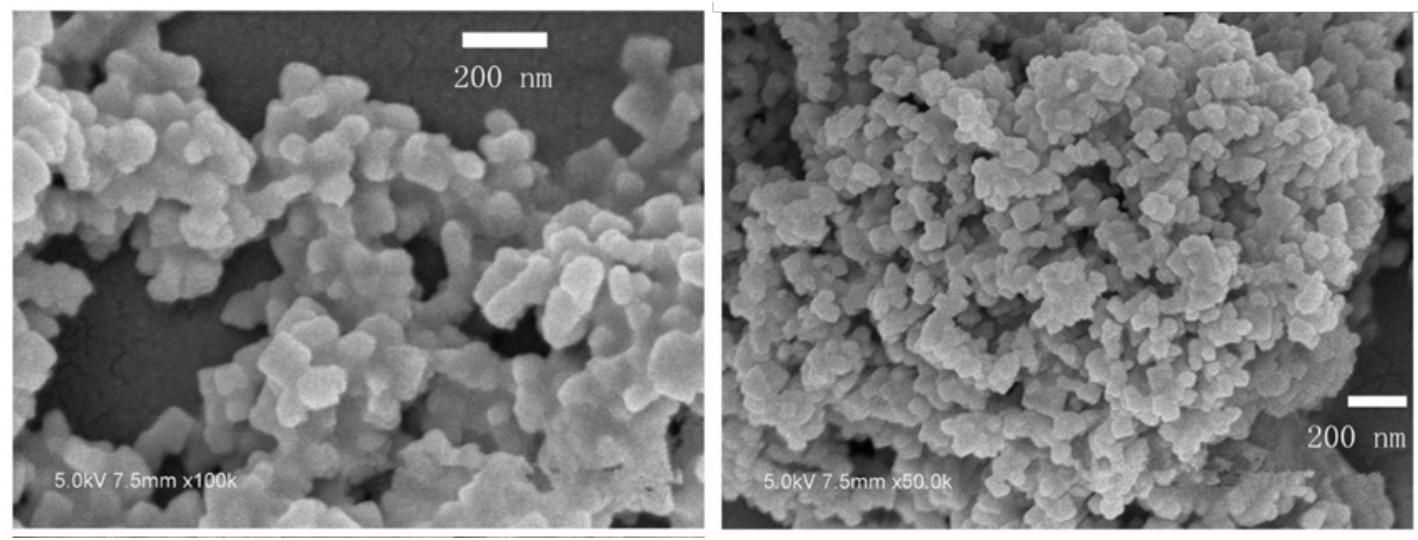

Figure 13. SEM images of $\mathrm{BiVO}_{4}: \mathrm{Eu}^{3+}$ (reaction time: 60 min upper; 100 min bottom). (Reproduced with permission from ref 44)

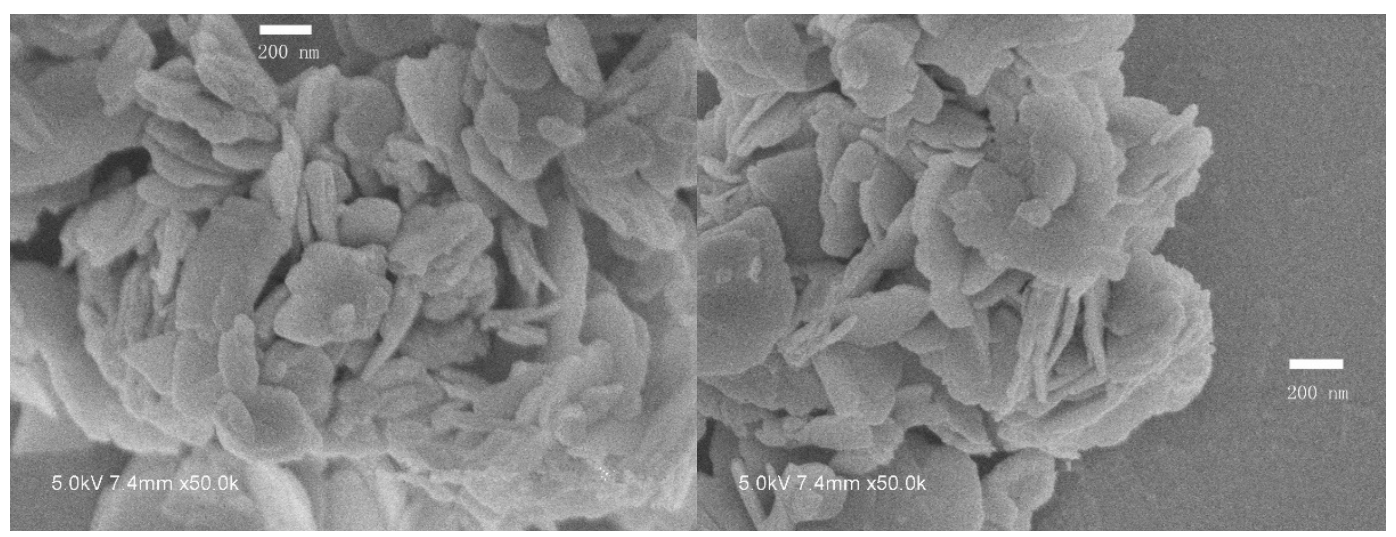

Figure 14. SEM images of $\mathrm{Gd}_{2}\left(\mathrm{MoO}_{4}\right)_{3}: \mathrm{Eu}^{3+}$ (Reproduced with permission from ref 44)

Yttrium aluminium garnet (YAG, $\mathrm{Y}_{3} \mathrm{Al}_{5} \mathrm{O}_{12}$ ) is a chemically stable laser material. Highly dispersed ultrafine YAG powder is necessary to obtain transparent YAG ceramics of high density. Si W. et al. described the preparation of YAG under US irradiation as well as under US and MW sequential irradiation [46]. Al and $\mathrm{Y}$ metal particles, isopropanol, $\mathrm{AlCl}_{3}$ and $\mathrm{NH}_{4} \mathrm{CO}_{3}$ were sonicated for 3-4 h. Several samples were irradiated with MW before calcination, for the sake of comparison. The TEM images of the different YAGs thus obtained demonstrated that US-MW irradiation produced a narrower distribution size and a more uniform shape than US assisted precipitation. Interestingly, it was demonstrated, using HRTEM images and FFT patterns, that single crystalline and crystal grains were grown in the same direction under US-assisted synthesis, while the US/MW-assisted synthesis gave crystal grain growth in random orientations (Fig. 15). MW irradiation produced molecular movement and has an effect on the energy distribution of the crystal planes meaning that the YAG particle size was finer and uniform, so as to avoid the addition of agents that suppress the agglomeration. 


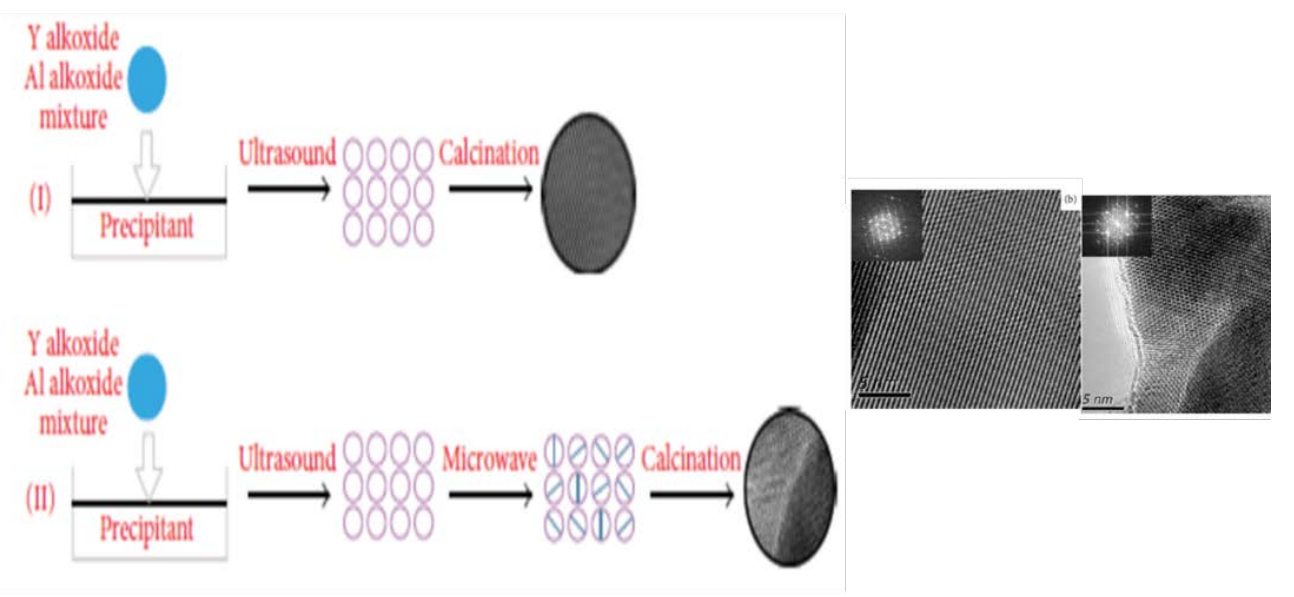

Figure 15. Reproduced with permission Ref 45

ZnOis a common photocatalyst that is active under ultraviolet light irradiation. In fact, nanoscaled $\mathrm{ZnO}$ is of very great interest indeed thanks to its unique optical and elective properties. $\mathrm{ZnO}$ microstructures exhibit enhanced performance over nanoparticles, nanorots and nanosheets. However, their preparation involves a complicated procedure and the addition of a surfactant or structure directing reagent. The synergic effect that MW and US provide allows for the preparation of well-defined flower-like nanostructures in surfactant-free conditions [47]. The optimized procedure entails sonication for $5 \mathrm{~min}$, at a power of $1000 \mathrm{~W}$, of a solution of zinc acetate in hydroxide aqueous solution, followed by treatment with MW heating combined with discontinuous US irradiation ( $1 \mathrm{~s}$ sonication and $2 \mathrm{~s}$ interruption) at a power of $500 \mathrm{~W}$ for $30 \mathrm{~min}$ (fig. 16). The flowerlike $\mathrm{ZnO}$ nanostructures showed superior methylene blue degradation catalytic activity to $\mathrm{ZnO}$ microrods.
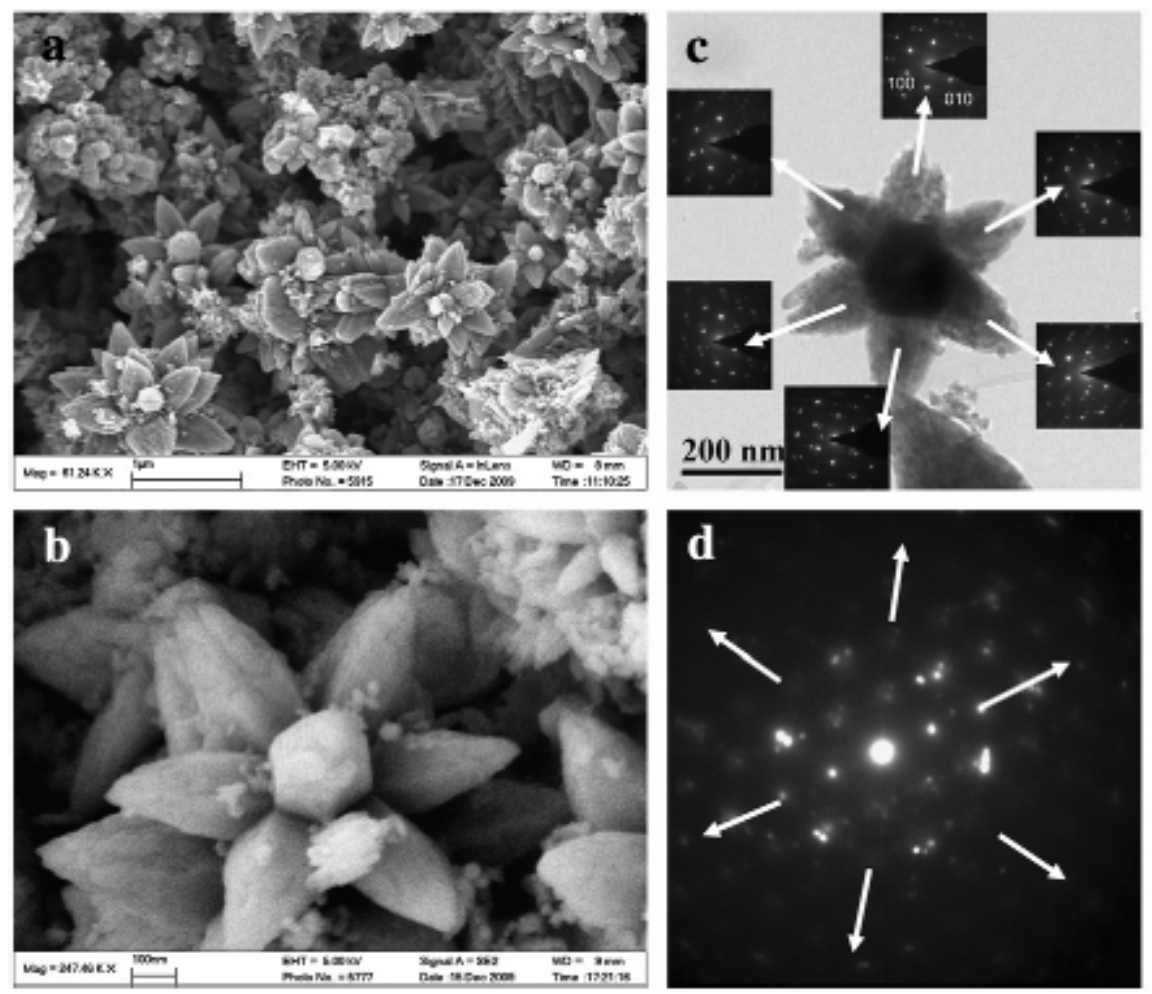
Figure 16. SEM images (a and b), TEM image (c) and SAED patterns (d and insets of $c$ ) of the flower-like $\mathrm{ZnO}$ nanostructures (Reproduced with permission Ref 46)

Another attempt at obtaining ZnAlO nanoparticles has been carried out with an eye to evaluating sterilization activity [48]. A homogeneous and stable dispersion of the crystal structure was obtained upon the subsequent US and MW irradiation of $\mathrm{Al}_{2}\left(\mathrm{SO}_{4}\right)_{3} \cdot 18 \mathrm{H}_{2} \mathrm{O}, \mathrm{Zn}\left(\mathrm{NO}_{3}\right)_{2} \cdot 6 \mathrm{H}_{2} \mathrm{O}$ (Molar ratio: $\mathrm{Al}_{2} \mathrm{O}_{3}: \mathrm{ZnO}=1: 100$ ) in deionised water with a dispersant. The smallest nanoparticles, of $20 \mathrm{~nm}$, showed the highest sterilization activity against the proliferation of $\mathrm{DH} 5$ a bacteria.

The micro- and nano-particles of bismuth vanadate $\left(\mathrm{BiVO}_{4}\right)$ have recently become the object of some interest as they show promise as visible light driven photocatalysts. Various $\mathrm{BiVO}_{4}$ nanostructures have been reported as promoting the degradation of numerous organic pollutants and microorganisms under visible light irradiation and it has been documented that the shape and size of the nanostructures both have a significant effect on activity. The controlled fabrication of the $m$-BiVO $\mathrm{B}_{4}$ nanostructure generally requires harsh conditions; high temperature, long reaction time, the addition of organic additives or a template. Combined MW/US irradiation is an attractive technique here as it enables the preparation of $\mathrm{BiVO}_{4}$ nanoparticles with an average size of $150 \mathrm{~nm}$ at $\mathrm{pH}=2$. At higher $\mathrm{pH}$ values, the growth process leads to microspheres with a diameter of $3 \mu \mathrm{m}(\mathrm{pH}=8)$ [49]. Different shapes were obtained with different solvents leading to a variety of nanostructures with differing optical properties and photocatalytic activity. The optimized procedure for $\mathrm{BiVO}_{4}$ micro-/nanostructure preparation is performed in a MW/US combined reactor at $110{ }^{\circ} \mathrm{C}$ (HC-300A, Beijing Xianghu Technology CO., Ltd, MW power $500 \mathrm{~W}$, US $800 \mathrm{~W}, 2$ s sonication and 1 interruption).

Cadmium sulfide (CdS) is an important direct band gap material that is widely used for optoelectronic applications. The preparation of the pure crystal is an object of interest in the fields of non-linear optical devices, lasers, thin film transistors, light emitting diodes and also in hydrothermal processes. SMUI has been used, by Guo et al., to control the syntheses of high purity nanostructures [50]. $\mathrm{CdCl}_{2}$ and either $\mathrm{CS}\left(\mathrm{NH}_{2}\right)_{2}$ or $\mathrm{C}_{2} \mathrm{H}_{5} \mathrm{NS}$ and sulphur were dissolved in ethylene glycol and heated, at 140 ${ }^{\circ} \mathrm{C}$ for $45 \mathrm{~min}$, by MW irradiation and sonicated in pulsed mode with a titanium horn. The CdS obtained was deeply characterized and hexagonal wurtzite crystals combined to obtain a nanoflower. A mixture of hexagonal and triangular pyramid nanostructures was observed when MW irradiation was used alone. The Photoluminescence spectra of the obtained CdS showed a large blue-shift in the flower nanostructure as compared to the simple 2D CdS nanostructure. In 2010, the same authors applied the optimized procedure to the preparation of Ag-doped CdS nanoparticles in an attempt to enhance their efficacy as photocatalysts [51]. CdS was doped with 1\%, 3\% and 5\% Ag+ which led to spherical crystals of $\sim 5-15 \mathrm{~nm}$ being obtained. This work investigated the contribution of US and MW to the phase evolution and it was observed that MW alone cannot induce chemical reaction while simultaneous pulsed US allows Ag to dissolve into the CdS matrix. The photocatalytic degradation of Rhodamine B occurs under visible light irradiation and only showed a slight improvement over the doped material when compared to CdS, because the doping ratio was not optimal.

Goethite and akageneite are ferric oxyhydroxides ( $\alpha$ - and $\beta$-FeOOH) that are employed in the degradation of organic compounds with hydrogen peroxide under relatively weak UV irradiation. Z. $\mathrm{Xu}$ et al. have published a paper on the preparation of $\alpha-\mathrm{FeOOH}$ via the SMUI of a $\mathrm{FeCl}_{3} \cdot 6 \mathrm{H}_{2} \mathrm{O}$ solution in urea and deionised water [52] A high-intensity ultrasonic probe (from Xinzhi Co., China, JY92-2D) with a $10 \mathrm{~mm}$ diameter titanium horn of $20 \mathrm{kHz}$ in a pulsed mode was used in this process. It had a duty cycle of $1 \mathrm{~s}$ and was directly immersed $1 \mathrm{~cm}$ into the solution. For the sake of comparison, the akageneite was also prepared under conventional conditions, under US and MW irradiation alone and using the combined method. The samples were all characterized by XRD and TEM. It was shown 
that morphologies depended greatly on the heating technique. As already observed for the preparation of $\mathrm{Pb}(\mathrm{OH}) \mathrm{Br}$ nanowires, the crystals are biggest under conventional conditions, while the smallest are obtained under SMUI. US used alone reduces crystal size and aggregation, while larger agglomeration was observed under $\mathrm{MW}$ irradiation alone. The $\beta$-FeOOH sample, prepared using SMUI (MW $400 \mathrm{~W}$, US $200 \mathrm{~W}$ ) at $70^{\circ} \mathrm{C}$ for $3 \mathrm{~h}$, gave the highest catalytic activity under visible light irradiation and shows promise for use in practical photo-Fenton-like processes which degrade organic pollutants.

\begin{tabular}{|l|l|l|}
\hline Preparation technique & $\begin{array}{l}\text { Width } \\
\text { (nm) }\end{array}$ & $\begin{array}{l}\text { Length } \\
\text { (nm) }\end{array}$ \\
\hline Convention condition & 75 & 250 \\
\hline MW & 25 & 80 \\
\hline US & 50 & 175 \\
\hline MW-US combined & 35 & 35 \\
\hline
\end{tabular}

Table 1. Comparison of conventional heating, MW, US and SMUI in the synthesis of $\beta$-FeOOH

Transition metal oxides like iron and titanium oxide show superior thermoelectric properties and high stability. Combining oxides with conducting materials, such as graphene, or doping polymers with graphene and an oxide provides significant increases in electric conductivity, as demonstrated by Dey A. et al. [53-55]. MW/US irradiation was used sequentially to obtain excellent oxide nanoparticle $\left(\mathrm{TiO}_{2}\right.$ and $\left.\mathrm{Fe}_{2} \mathrm{O}_{3}\right)$ dispersion over graphene. Anatase $\mathrm{TiO}_{2}$ nanoparticles were supported on graphene and the composite was studied as a burn rate enhancer and a combustion catalyst for the decomposition of ammonium perchlorate. The graphene- $\mathrm{TiO}_{2}$ and $\mathrm{Fe}_{2} \mathrm{O}_{3}$ nanocomposites were then dispersed in $20 \%$ polyvinyl acetate and used successfully as thermoelectric polymers.

The MW/US combination has also been used for the preparation of zeolite with the aim of making it mesoporous and improving its catalytic activity [56]. The strategy for the preparation was based on the addition of an ionic liquid (1-methyl-3-[3'-(trimethoxysilyl) propyl] imidazolium chloride) for use as a mesoporous structure directing template (Fig. 17). SMUI facilitated the hydrothermal crystallization of the Al silicate gel containing IL at $80{ }^{\circ} \mathrm{C}$ for $10 \mathrm{~min}(200 \mathrm{~W})$ and did so in a shorter crystallization time than the conventional process. A detailed characterization of the zeolite showed that the structure obtained under SMUI had increased surface area and pore volume. The micromesoporous zeolite exhibited a well-dispersed, cauliflower-like morphology and a more uniform particle size. Catalytic activity was investigated on the alkylation reaction of styrene with $o$-xylene. The SMUI obtained catalyst gave higher yields as well as improved stability and reusability.

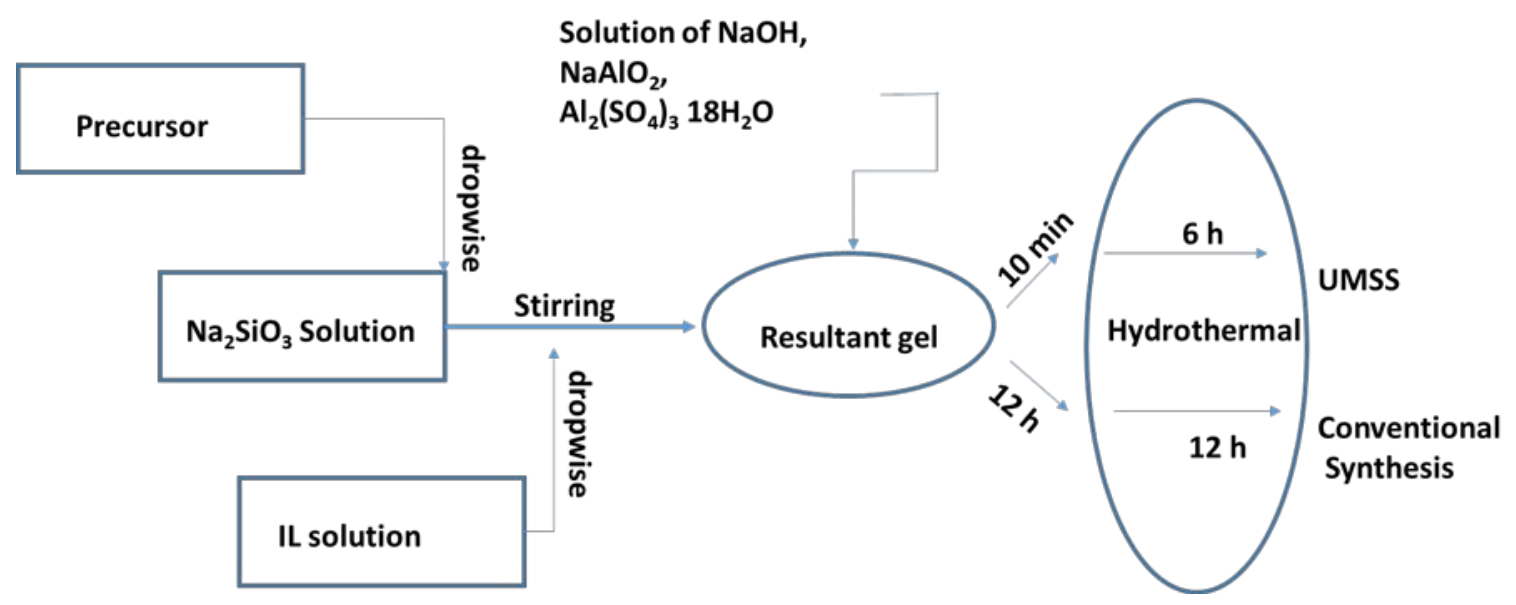


Figure 17. Schematic representation of micro-mesoporous zeolite $\mathrm{Y}$ synthesis by SMUI and conventional synthesis

Nano-Hydroxyepatite has been obtained using the combined MW-US technique which was used with an eye to improving its performance in adsorbing fluorine from contaminated water $[57,58]$. The two published procedures solubilized $\mathrm{Ca}\left(\mathrm{NO}_{3}\right)_{2} \cdot 4 \mathrm{H}_{2} \mathrm{O}$ in water at $\mathrm{pH}$ values from 10.8 to 9.0. After the addition of $\mathrm{KH}_{2} \mathrm{PO}_{4}$ or $\left(\mathrm{NH}_{4}\right)_{2} \mathrm{HPO}_{4}$, the sample was treated with SMUI until a white agglomerate mass was produced. One of the procedures pre-treated the mixture with US (50 W, $30 \mathrm{~Hz}$ ) for $1 \mathrm{~h}$ before SMUI. Ultrafine and highly crystalline particles of uniform size were obtained.

The sorption capacity of nano-HAp for the removal of fluoride ions from test solutions of fluorine in water was found to be higher than other synthetic nano-HAp materials reported in the literature. Analogously, Liang et al. obtained mesoporous hydroxyapatite nanoparticles using SMUI [59]. In this publication, it was found that flake-like morphology without a mesoporous structure was recovered at low $\mathrm{MW}$ power and temperature $\left(10\right.$ to $\left.50{ }^{\circ} \mathrm{C}\right)$, while a clear mesoporous derivative was observed when the reaction was carried out from $50^{\circ} \mathrm{C}$ to $90^{\circ} \mathrm{C}$. An increase in MW power, from 50 to $200 \mathrm{~W}$, furnished a more mesoporous structure, whereas prolonging the MW irradiation, from 10 to $30 \mathrm{~min}$, did not influence the morphology of the nanoparticles.

\section{Plant Extraction}

Both MW-assisted extraction (MAE) and US-assisted extraction (UAE) have been used independently in the extraction of vegetable matrices [60] and in efficient green extractions [61]. US alone improves extraction as cavitation disrupts cell walls, thereby releasing soluble components into the solution and increasing mass transfer. MW causes efficient in-core heating and promotes the migration of dissolved ions and polar species. Combined irradiation increases the solubility, and hence yields, of extracted compounds and requires less time than either source alone. Prolonged irradiation, however, may lead to the partial degradation of sensitive molecules. Simultaneous irradiation has thus been successfully employed in the extraction of essential oils from soybean germ and marine microalgae [62].

\section{Conclusion}

A number of papers have reported on environmentally friendly applications which use combined MW-US irradiation in a number of fields, including organic/inorganic synthesis, pollutant degradation, chemical digestion and even plant extraction. Besides the nanoparticle preparation and the heterogeneous phase reaction, any predictable rule in term of expected organic reaction to be improved by the SMUI cannot be exploited The present review summarizes such developments and gives insight into future possibilities in particular in nanoparticles preparation and heterogeneous catalysis. Process implementation and scale-up to pilot plants have also been highlighted, although industrial applications will need specialised engineering design. We believe that, as time passes, non-conventional hyphenated techniques and hybrid reactors will be recognised still further as a powerful ally to green synthetic chemistry and beyond.

\section{Acknowledgments}


The University of Turin is warmly acknowledged for its financial support (Fondi Ricerca Locale 2015).

\section{References}

1. Maeda M, Amemiya H. (1995) Chemical effects under simultaneous irradiation by microwaves and ultrasound, New J. Chem. 19:1023-1028.

2. Cravotto G, Cintas, P (2007). The combined use of microwaves and ultrasound: new tools in process chemistry and organic synthesis, Chem. Eur. J. 13:1902-1909.

3. Cravotto G, Borretto E, Oliverio M, Procopio A, Penoni A (2015) Catalysis in water or biphasic aqueous systems under sonochemical conditions, Catal. Commun. 63:2-9.

4. Cintas P, Cravotto G, Canals A (2012) Combined ultrasound-microwave technologies, in Handbook on Applications of Ultrasound: Sonochemistry for Sustainability, CRC Press, Boca Raton, FL Chap. 25, pp. 659-673.

5. Cravotto G, Cintas, P. (2006) Power ultrasound in organic synthesis: moving cavitational chemistry from academia to innovative and large-scale applications, Chem. Soc. Rev. 35:180196.

6. Cravotto G, Garella D, Calcio Gaudino E, Lévêque, J.M. (2008) Microwaves-Ultrasound Coupling: A tool for Process Intensification in Organic Synthesis Chem. Today 26:39-41.

7. Chemat F, Poux M, Di Martino JL, Berlan J, (1996) An original microwave-ultrasound combined reactor suitable for organic synthesis: application to pyrolysis and esterification, $\mathrm{J}$. Microwave Power Electromagn. Energy 31:19-22.

8. Cravotto G, Beggiato M, Penoni A, Palmisano G, Tollari S, Lévêque JM, Bonrath W, (2005) High-Intensity Ultrasound and Microwave, Alone or Combined, Promote Pd/C-Catalyzed ArylAryl Couplings, Tetrahedron Lett. 46:2267-2271.

9. Cravotto G, Di Carlo S, Curini M, Tumiatti V, Roggero C, (2007) A New Flow Reactor for the Treatment of Polluted Water with Microwave and Ultrasound J. Chem. Technol. Biotech. 82:205-208.

10. Wu Z, Ondruschka B, Cravotto G, (2008) Degradation of Phenol under Combined Irradiation with Microwaves and Ultrasound, Environ. Sci. \& Technol. 42: 8083-8087.

11. Ragaini V, Pirola C, Borrelli S, Longo I (2012) Simultaneous ultrasound and microwave new reactor: detailed description and energetic consideration. Ultrason. Sonochem. 19:872-876

12. Otteson D, Michl J, (1984) A procedure for gas-phase dehalogenation of organic dihalides with alkali metal vapors using microwave and/or ultrasound excitation and matrix isolation of products J. Org. Chem., 49, 866-873.

13. Cravotto G, Rinaldi L, Carnaroglio D, (2015) Efficient Catalysis by combining Microwaves with other enabling Technologies, Chapt. 8 in Microwaves in Catalysis Ed. Horikoshi S, Serpone N, Wiley-VCH Verlag GmbH \& Co. KGaA Boschstr. 12, 69469 Weinheim, Germany.

14. Martinez-Guerra E, Gnaneswar Gude V (2014) Synergistic effect of simultaneous microwave and ultrasound irradiations on transesterification of waste vegetable oil. Fuel 137:100-108.

15. Martinez-Guerra E, Gnaneswar Gude V (2014) Transesterification of used vegetable oil catalyzed by barium oxide under simultaneous microwave and ultrasound irradiations. Energy Convers. Manage. 88:633-640.

16. Martinez-Guerra E, Gude V G (2016) Alcohol effect on microwave-ultrasound enhanced transesterification reaction Chem. Eng. Process. 101, 1-7. 
17. Ardebili SMS, Hashjin TT, Ghobadian B , Najafi G, Mantegna S, Cravotto G (2015) Optimization of biodiesel synthesis under simultaneous ultrasound-microwave irradiation using response surface methodology (RSM). Green Process Synth 4:259-267.

18. Palmisano G, Bonrath W, Boffa L, Garella D Barge A, Cravotto G ( 2007) Heck Reactions with Very Low Ligandless Catalyst Loads Accelerated by Microwaves or Simultaneous Microwaves/Ultrasound Irradiation. Adv. Synth. Catal. 349:2338-2344.

19. Sacco M, Charnay C, De Angelis F, Radoiu M, Lamaty, F, Martinez J , Colacino E. (2015) Microwave-ultrasound simultaneous irradiation: a hybrid technology applied to ring closing Metathesis. RSC Adv. 5:16878-16885.

20. Palmisano G, Tagliapietra S, Binello A, Boffa L, Cravotto G (2007), Efficient regioselective opening of epoxides by nucleophiles in water under simultaneous ultrasound/microwave irradiation Synlett 2041-2044.

21. Cintas P, Martina K, Robaldo B, Garella D, Boffa L, Cravotto G. (2007) Improved Protocols For Microwave-Assisted Cu(I)-Catalyzed Huisgen 1,3-Dipolar Cycloadditions. Collect. Czech. Chem. Commun. 1014-1024.

22. Cintas P, Barge A, Tagliapietra S, Boffa L, Cravotto G (2010) Alkyne-azide click reaction catalyzed by metallic copper under ultrasound. Nature Protocol 5:607-616.

23. Peng Y, Song G (2003) Combined microwave and ultrasound accelerated Knoevenagel-Doebner reaction in aqueous media: a green route to 3-aryl acrylic acids. Green Chemistry 5:704-706.

24. Peng Y, Song G (2002) Combined microwave and ultrasound assisted Williamson ether synthesis in the absence of phase-transfer catalysts. Green Chemistry 4:349-351.

25. Peng Y, Song G (2001) Simultaneous microwave and ultrasound irradiation: a rapid synthesis of hydrazides .Green Chemistry 3:302-304.

26. Wu Z, Ondruschka B, Cravotto G, Garella D, Asgari J (2008) Oxidation of Primary Aromatic Amines under Irradiation with Ultrasound and/or Microwaves. Synthetic Communications 38:2619-2624.

27. Garella D., Tagliapietra S., Metha V.P., Van der Eycken E., Cravotto G. (2010) Straightforward Functionalization of 3,5-Dichloro-2-pyrazinones under Simultaneous Microwave and Ultrasound Irradiation. Synthesis 136-140.

28. Cravotto G, Boffa L, Levêque JM, Estager J, Draye, M, Bonrath W (2007) A Speedy One-Pot Synthesis of Second-Generation Ionic Liquids Under Ultrasound and/or Microwave Irradiation. Aust. J. Chem. 60:946-950.

29. Domini C, Vidal L, Cravotto G, Canals A (2009) A simultaneous, direct microwave/ultrasoundassisted digestion procedure for the determination of total Kjeldahl nitrogen. Ultrason. Sonochem. 16:564-569.

30. Cui Y, Lieber C M, (2001) Functional Nanoscale Electronic Devices Assembled Using Silicon Nanowire Building Blocks Science 291: 851-253.

31. Boffa L, Tagliapietra S, Cravotto G, (2013) Combined energy sources in the synthesis of nanomaterials in Microwaves 55-74. Chapt. 4 in Nanoparticle Synthesis - Fundamentals and Applications. Ed. Horikoshi S, Serpone N, Wiley-VCH Verlag GmbH \& Co. KGaA Boschstr. 12, 69469 Weinheim, Germany.

32. Bang J H, Suslick K S, (2010) Application of ultrasound to the nanostructured materials Adv Mater 22: 1039-1059.

33. J. C. Colmenares (2014) Sonication-Induced Pathways in the Synthesis of Light-Active Catalysts for Photocatalytic Oxidation of Organic Contaminants ChemSusChem 7, 1512-1527

34. Cravotto G, Boffa L, (2014) Combined Ultrasound-Microwave irradiation for the preparation of nanomaterials, 203-226. Chapt. 7, in Cavitation - A Novel Energy Efficient Technique for the 
Generation of Nanomaterials Ed. by Sivakumar M, Ashokkumar M, Pan Stanford Publishing Pte Ltd., eBook ISBN: 978-981-4411-55-4.

35. Feng H, Li Y, Lin S, V Van der Eycken E, Song G (2014) Nano Cu-catalyzed efficient and selective reduction of nitroarenes under combined microwave and ultrasound irradiation. Sustain Chem Process 2:14-19.

36. Wu Z, Cherkasov N, Cravotto G, Borretto E, Ibhadon A O, Medlock J, Bonrath W (2015) Ultrasound- and Microwave-Assisted Preparation of Lead-Free Palladium Catalysts: Effects on the Kinetics of Diphenylacetylene Semi-Hydrogenation. ChemCatChem 7:952-959.

37. Zhu H T, Zhang C Y, Tang Y M, Wang J X (2007) Novel synthesis and thermal conductivity of CuO nanofluid. J Phys Chem C 111:1646-1650.

38. Shen X-F, (2009) Combining microwave and ultrasound irradiation for rapid synthesis of nanowires: a case study on $\mathrm{Pb}(\mathrm{OH}) \mathrm{Br}$. J Chem Technol Biotechnol 84: 1811-1817.

39. Guo Q J, Ford G M, Yang W C, Walker B C, Stach E A, Hillhouse H W, Agrawal R (2010) Fabrication of 7.2\% Efficient CZTSSe Solar Cells Using CZTS Nanocrystals. J Am Chem Soc 132:17384-17386.

40. Zhou Y L, Zhou W H, Du Y F, Li M, Wu S X (2011) Sphere-like kesterite $\mathrm{Cu}_{2} \mathrm{ZnSnS}_{4}$ nanoparticles synthesized by a facile solvothermal method. Mater Lett 65:1535-1537.

41. Wang Y, Gong H, (2011) Cu2ZnSnS4 synthesized through a green and economic process. J Alloy Compd 509:9627-9630.

42. Madiraju V A, Taneja K, Kumar M, Seelaboyina R (2016) CZTS synthesis in aqueous media by microwave irradiation J Mater Sci: Mater Electron, 27: 3152-3157.

43. Wang W, Shen H, Yao H, Li J, Jiao J (2015) Influence of solution temperature on the properties of $\mathrm{Cu}_{2} \mathrm{ZnSnS}_{4}$ nanoparticles by ultrasound-assisted microwave irradiation J Mater Sci Mater El, 26:1449-1454.

44. Long F, Chi S, He J, Wang J, Wu X, Mo S, Zou Z (2015) Synthesis of hexagonal wurtzite $\mathrm{Cu}_{2} \mathrm{ZnSnS}_{4}$ prisms by an ultrasound-Assisted microwave solvothermal method. J Solid State Chem 229: 228-234.

45. Zheng Y, Tan J, Huang L, Tan D, Li Y, Lin X, Huo S, Lin J, Wang Q (2013) Sonochemistryassisted microwave synthesis of nano-sized lanthanide activated phosphors with luminescence and different microstructures. Mater Lett 113:90-92.

46. Si W, Ding C, Ding S (2014) Synthesis and Characterization of YAG Nanoparticles by Ultrasound-Assisted and Ultrasound-Microwave-Assisted Alkoxide Hydrolysis Precipitation Methods, J Nanomaterials. Article ID 408910.

47. Li H, Liu E, Chan F Y F, Lu Z, Chen R (2011) Fabrication of ordered flower-like ZnO nanostructures by a microwave and ultrasonic combined technique and their enhanced photocatalytic activity. Mater Lett 65:3440-3443.

48. Luo C-X , Liu J-K, Lu Y, Du C-S (2012) Controllable preparation and sterilization activity of zinc aluminium oxide nanoparticles Mater Sci Eng C 32:680-684.

49. Zhang Y, Li G, Yang $\mathrm{X}$, Yang $\mathrm{H}$, Lu Z, Chen $\mathrm{R}$ (2013) Monoclinic $\mathrm{BiVO}_{4}$ micro/nanostructures: Microwave and ultrasonic wave combined synthesis and their visible-light photocatalytic activities J Alloy Compd 551:544-550.

50. Tai G, Guo W (2008) Sonochemistry-assisted microwave synthesis and optical study of singlecrystalline CdS nanoflowers. Ultrason Sonochem 15:350-356.

51. Ma J, Tai G, Guo W (2010) Ultrasound-assisted microwave preparation of Ag-doped CdS nanoparticles Ultrasonics Sonochem 17: 534-540.

52. Xu Z, Yu Y, Fang D, Xu J, Liang J, Zhou L (2015) Microwave-ultrasound assisted synthesis of $\beta$-FeOOH and its catalytic property in a photo-Fenton-like process Ultrasonics Sonochemistry 27:287-295. 
53. Dey A, Panja S, Sikder A K, Chattopadhyay S (2015) One pot green synthesis of graphene-iron oxide nanocomposite (GINC): an efficient material for enhancement of thermoelectric performance. RSC Adv 5:10358-10364.

54. Dey A, Hadavale S, Khan M A S, More P, Khanna P K, Sikder A K, Chattopadhyay (2015) S Polymer based graphene/titanium dioxide nanocomposite (GTNC): an emerging and efficient thermoelectric material. Dalton Trans. 44: 19248-19255.

55. Dey A, Nangare V, More P V, Shageeuulla Khna M A, Khanna P V, Kanti Sikder A, Chattopadhyay S (2015) A graphene titanium dioxide nanocomposite (GTNC): one pot green synthesis and its application in a solid rocket propellant RSC Adv 5:63777-63785.

56. Fu X, Sheng X, Zhou Y, Fu Z, Zhao S, Zhang Z, Zhang Y (2016) Ultrasonic/microwave synergistic synthesis of well-dispersed hierarchical zeolite Y with improved alkylation catalytic activity. Korean J. Chem. Eng., 33:1931-1937.

57. Poinerna G E J, Ghoshc M K, Nga Y-J, Issa T B (2011) Defluoridation behavior of nanostructured hydroxyapatite synthesized throughan ultrasonic and microwave combined technique. J Hazard Mater 185:29-37.

58. Zou Z, Lin K, Chen L, Chang J (2012) Ultrafast synthesis and characterization of carbonated hydroxyl apatite nanopowders via sonochemistry-assisted microwave process Ultrason Sonochem 19:1174-1179.

59. Liang T, Qian J, Yuan Y, Liu C (2013) Synthesis of mesoporous hydroxyapatite nanoparticles using a template-free sonochemistry-assisted microwave method. J Mater Sci 48:5334-5341

60. Cravotto G, Cintas P, Modifying Flavour in Food (Eds.: A. Taylor, J. Hort), Woodhead Publishing Ltd./CRC Press, Cambridge, UK, 2007, pp. 41-63.

61. Chemat F, Abert-Vian M, Cravotto G (2012) Review: Green Extraction of Natural Products: Concept and Principles, Int. J. Mol. Sci. 13:8615-8627.

62. Cravotto G, Boffa L, Mantegna S, Perego P, Avogadro M, Cintas P, (2008) Improved extraction of natural matrices under high-intensity ultrasound and microwave, alone or combined, Ultrason. Sonochem. 15:898-902. 